Bugella Altamirano, M. (2019): “Arqueología para después de una guerra: Enrique Romero de Torres y la Comisaría General de Excavaciones Arqueológicas en Córdoba", Spal 28.1: 261-280. DOI: http://dx.doi.org/10.12795/spal.2019.i28.11

\title{
ARQUEOLOGÍA PARA DESPUÉS DE UNA GUERRA: ENRIQUE ROMERO DE TORRES Y LA COMISARÍA GENERAL DE EXCAVACIONES ARQUEOLÓGICAS EN CÓRDOBA
}

\section{ARCHAEOLOGY AFTER A CIVIL WAR: ENRIQUE ROMERO DE TORRES AND THE COMISARÍA GENERAL DE EXCAVACIONES ARQUEOLÓGICAS IN CÓRDOBA}

\author{
MATILDE BUGELLA ALTAMIRANO \\ Equipo de Trabajo Proyecto DIDACTA (HAR2015-66753-R).Correo-e: mbugalt@gmail.com
}

Resumen: Ofrecemos en el presente trabajo la actividad arqueológica desarrollada en Córdoba durante el periodo en que estuvo al frente de la Comisaría de Excavaciones el primero de sus comisarios provinciales, Enrique Romero de Torres; una etapa, la primera postguerra, marcada por la escasez de medios materiales y por la depuración política sufrida por miembros de la intelectualidad local especialmente vinculados a la Arqueología, como Samuel de los Santos Gener, que sucedería en el cargo de comisario a Romero de Torres. Ambos investigadores representaron en Córdoba a la Comisaría General de Excavaciones Arqueológicas, institución muy controvertida por el personalismo de su director, Julio Martínez Santa-Olalla, y por la no profesionalización de sus integrantes, titulares de un cargo honorífico que conllevaba sin embargo una abrumadora carga de trabajo. Contamos para su estudio, junto a las publicaciones que de sus trabajos realizaron los investigadores mencionados, con dos fuentes fundamentales: el archivo familiar Romero de Torres y el Registro de hallazgos arqueológicos en la provincia de Córdoba, que llevó diariamente Santos Gener; una rica y variada documentación lo suficientemente ilustrativa como para permitirnos conocer el lento y duro esfuerzo de recuperación de una mínima normalidad investigadora durante el difícil periodo del primer franquismo.

Palabras clave: Franquismo, protección del patrimonio, yacimiento arqueológico, tráfico de antigüedades, arqueología amateur.
Summary: We offer with this paper the archaeological activity carried out in Cordoba during the period in which Enrique Romero de Torres, the first of a series of provincial $\mathrm{co}^{-}$ misarios, directed the Comisaria de Excavaciones. A period, the first postwar, marked by poverty and by the purge suffered by members of the local intelligentsia linked to Archaeology, such Samuel de los Santos Gener, who succeeded Romero de Torres as comisario. Both scholars represented the Comisaría General de Excavaciones Arqueológicas in Cordoba, a very controversial institution due to the egotism of its Director, Julio Martínez Santa-Olalla, and by the amateurism of ist members, holders of an honorary position that entailed an enormous amount of work. Beside the papers published by the aforementioned scholars, this research would not have been possible if it had not been for two primary documentary sources: the Romero de Torres family's archive and the Registro de hallazgos arqueológicos en la provincia de Córdoba, daily kept by Santos Gener. Both constitute a rich and varied collection of documents, illustrative enough to allow us to know the slow and tough recovery of a minimum normality in the archaeological research during the harsh first period of the Franco regime.

Key words: franco regime, protection of the historical heritage, archaeological site, antiquities trade, amateur Archaeology. 


\section{INTRODUCCIÓN}

La actividad de Enrique Romero de Torres como Comisario Provincial de Excavaciones tiene lugar durante una etapa, la de la primera postguerra, marcada por la inevitable cesura que la Guerra Civil introdujo en la investigación arqueológica realizada en Córdoba durante el primer tercio del siglo. A la paralización de las excavaciones llevadas a cabo en sus dos principales monumentos islámicos, Mezquita Aljama y Madinat al-Zahra, viene a añadirse el proceso de depuración política sufrido por dos miembros de la intelectualidad local especialmente vinculados a la Arqueología, Samuel de los Santos Gener, director del Museo Arqueológico Provincial, y Rafael Castejón y Martínez de Arizala, delegado-presidente de la Comisión DelegadoDirectora encargada de las excavaciones en la ciudad palatina (Garriguet 2009/10: 12-13; Aguilar et al. 2014: 251-254). Finalmente, la inevitable escasez de medios materiales convertía los hallazgos casuales en tesoros más codiciados que nunca, al tiempo que dificultaba la reanudación de las excavaciones y el traslado del $\mathrm{Mu}-$ seo Arqueológico a un nuevo edificio.

La actividad desarrollada en Córdoba por la Comisaría General de Excavaciones Arqueológicas (en adelante CGEA), nos permite conocer el lento y duro esfuerzo de recuperación de una mínima normalidad investigadora durante la que quizá sea la etapa menos conocida de la institución (Díaz-Andreu y Ramírez 2001: 329 y 343). Junto a las publicaciones que de sus trabajos realizaron los investigadores mencionados, singularmente los artículos aparecidos en el Boletín de la Real Academia de Córdoba, disponemos para su estudio de una fuente primordial, como es el fondo documental de la familia Romero de Torres. Depositado en el Archivo Provincial de Córdoba, permite conocer la actividad desarrollada por Enrique Romero de Torres no solo como comisario provincial, sino asimismo en tanto que miembro de la Comisión Provincial de Monumentos de Córdoba (en adelante CPM), institución de la que fue secretario, y como investigador y arqueólogo, faceta esta última en la que destacan las excavaciones que realizó durante la década de los treinta en el área funeraria del Camino Viejo de Almodóvar. Contamos como referencias complementarias con el archivo del Museo Arqueológico Nacional y con el Registro de hallazgos arqueológicos en la provincia de Córdoba, recogidos y croquizados diariamente, redactado por Samuel de los Santos Gener (Santos 1958), del que hemos podido consultar la copia conservada en el Centro CIL II. Lamentablemente, no ha sido posible acceder a los fondos del archivo Santa-Olalla del Museo de San Isidro de Madrid (Quero 2015), cerrado temporalmente, cuando se preparaba este artículo, por trabajos internos de revisión y ordenación, motivos similares a los que impiden de momento a los investigadores consultar el archivo del Museo Arqueológico de Córdoba. Finalmente, el Archivo General de la Administración conserva series documentales sobre Asuntos Generales de Museos y Excavaciones y expedientes personales cuya consulta debemos agradecer a los autores que nos han precedido en la investigación del periodo que nos ocupa, especialmente a los trabajos publicados por M. Díaz-Andreu, M. Ramírez y F. Gracia.

\section{LA ARQUEOLOGÍA ESPAÑOLA DURANTE EL PRIMER TERCIO DEL SIGLO XX: DE LA LEY DE EXCAVACIONES A LA CGEA}

El primer tercio del siglo XX ha sido calificado por $\mathrm{M}$. Díaz-Andreu como las «décadas de oro de la Arqueología española» (Díaz-Andreu 2002: 41 y ss.). El mismo año, 1900, en que el estudio de la Arqueología adquiere rango universitario se crea el Ministerio de Instrucción Pública y Bellas Artes, dentro del cual la Dirección General de Bellas Artes (en adelante DGBA) sería el órgano administrativo que, desde su creación en 1915 hasta la descentralización promovida por la Constitución de 1978, articularía la actuación del Estado en materia de cultura y protección del patrimonio (Cabello 2013). La Arqueología se beneficia asimismo de la construcción de un marco normativo que, superando la anterior inhibición del Estado liberal, implica progresivamente a los poderes públicos en la protección del patrimonio cultural (Bugella 2017a). Sus dos grandes pilares serían la Ley de Excavaciones y Antigüedades, de 7 de julio de 1911, donde por primera vez se define la excavación arqueológica como las «remociones deliberadas y metódicas de terrenos respecto á los cuáles existan indicios de yacimientos arqueológicos» (art. 1), y la Ley de 13 de mayo de 1933, relativa al Patrimonio Artístico Nacional, eje central, en palabras de J. M. Alegre, «en torno al cual ha girado la reglamentación del sector hasta la promulgación de la Ley del Patrimonio Histórico Español de 15 de junio de 1985» (Alegre 1994: vol. 1, 119).

Apenas iniciada la Guerra Civil, la Orden de 23 de diciembre de 1936 estableció el nombramiento en todas las provincias de la denominada zona nacional de una Junta de Cultura Histórica y del Tesoro Artístico, con la misión de recabar información sobre monumentos y 
obras de arte que hubieran desaparecido o sufrido daños de importancia con posterioridad al 14 de abril de 1931. Meses después, la Orden de 14 de enero de 1937 creó un Servicio Artístico de Vanguardia, dependiente en sus actuaciones de dichas Juntas de Cultura, para la recuperación y custodia de obras de arte o edificios en las zonas que fueran siendo ocupadas (Gracia 2009: 29-30).

Esas primeras iniciativas fueron poco más que «un salvamento o recuperación de materiales procedentes de los territorios progresivamente ocupados» (Gracia 2009: 30). Hasta 1938 no se organizaría una estructura vertebrada destinada a la protección del patrimonio, el Servicio de Defensa del Patrimonio Artístico Nacional (en adelante SDPAN), al que, por Decreto de 22 de abril de 1938, se transfirieron las atribuciones de las Juntas de Cultura. El SDPAN estaba integrado por una Comisaría Central, a cuyo frente se encontraba un Comisario General, y nueve Comisarías de Zona. Tenía como misión conservar y reconstruir los bienes inmuebles del patrimonio artístico deteriorados durante la contienda, así como recuperar las obras de arte en posesión del gobierno republicano (Díaz-Andreu y Ramírez 2001: 326-327; Gracia 2009: 30-39). Su jerarquizada estructura sería heredada por el organismo llamado a reorganizar de manera permanente la gestión del patrimonio arqueológico, la Comisaría General de Excavaciones Arqueológicas, ideada y dirigida, en calidad de Comisario General, por Julio Martínez Santa-Olalla.

Santa-Olalla aspiraba a concentrar en la CGEA toda la actividad arqueológica realizada en España. Su disposición fundacional, la Orden de 9 de marzo de 1939, le transfería las competencias en Arqueología, si bien la nueva institución se encontraba bajo la dependencia jerárquica de la DGBA, con cuyo Director General, el marqués de Lozoya, los conflictos fueron frecuentes (Mederos 2003/04: 35; Gracia 2009: 228-229; Gozalbes 2015: 6). La no profesionalización de los comisarios provinciales fue además muy polémica. Dada la no remuneración de sus funciones, ocuparon el cargo de comisario durante esta «era dorada de los no profesionales» (Lucas 1991: 238) eruditos con afición por la Arqueología que contaban con otras fuentes de ingresos.

Pese a su personalismo, no puede negársele a SantaOlalla una gran energía y capacidad emprendedora, junto a una mentalidad innovadora en varios aspectos, como su interés por la fotografía aérea, o por la difusión de la Arqueología en la sociedad (Castelo et al. 1997: 573-578: Blánquez y Roldán 2011/12: 60-63). Reconoce M. Díaz-Andreu que, si bien la calidad de lo organizado deja mucho que desear, «quizá un muro de silencio creado por parte de quienes terminaron hundiendo a Martínez Santa-Olalla pueda explicar la falta de influencia posterior, y quizá sea necesario hacer un estudio de impacto consultando las fuentes de la época, tanto académicas como periodísticas» (Díaz-Andreu 2003: 48).

\section{LA COMISARÍA PROVINCIAL DE EXCAVACIONES DE CÓRDOBA}

Con la creación del SDPAN Andalucía quedó dividida en dos Comisarías, las de Andalucía Alta (Granada) y Andalucía Baja (Sevilla). Córdoba formaba parte de esta última, para la que fue nombrado comisario el entonces gobernador civil de Sevilla, Pedro Gamero del Castillo (Gracia 2009: 32-33). La CGEA adopta la misma estructura, regulando la Orden de 12 de agosto de 1939 la actividad de comisarios y Comisarías de Zona. Debían aquellos informar a la Comisaría General de las principales obras de arte y monumentos de su zona, valorar el coste de su mantenimiento y proponer un plan de protección, ejecutándolo una vez fuese aprobado. Sin embargo, dos años más tarde la Orden de 30 de abril de 1941, que autorizaba a la DGBA a nombrar comisarios de excavaciones, únicamente menciona a estos, dejando de facto la CGEA estructurada en base a un organigrama presidido por el comisario general, del que dependían las Comisarías Provinciales y Locales. La mayoría de los comisarios fueron reclutados entre los directores de museos. Ese fue el caso de Enrique Romero de Torres, director del Museo de Bellas Artes de Córdoba y comisario provincial entre 1941 y 1946, y de Samuel de los Santos Gener, director del Museo Arqueológico Provincial (figs. 1 y 2). Este último, tras ejercer desde 1941 como comisario local de Córdoba, ocuparía el cargo de comisario provincial en sustitución de Romero de Torres entre 1947 y 1955 (Díaz-Andreu 2011: 40-41).

Enrique Romero de Torres nació en Córdoba en 1872, ciudad en la que su padre, Rafael Romero Barros, ocupaba desde 1862 la plaza de conservador-restaurador del Museo Provincial. De formación artística, tras una estancia en Madrid truncada por el fallecimiento de este ingresa en 1896 en las academias de Bellas Artes de San Fernando y de Córdoba. Consigue ese mismo año la plaza de profesor asociado a la Cátedra de Dibujo del Adorno en la Escuela Provincial de Bellas Artes, y el nombramiento, por la CPM, de conservador interino del Museo Provincial, institución de la que llegaría a ser director, permaneciendo al frente del mismo 

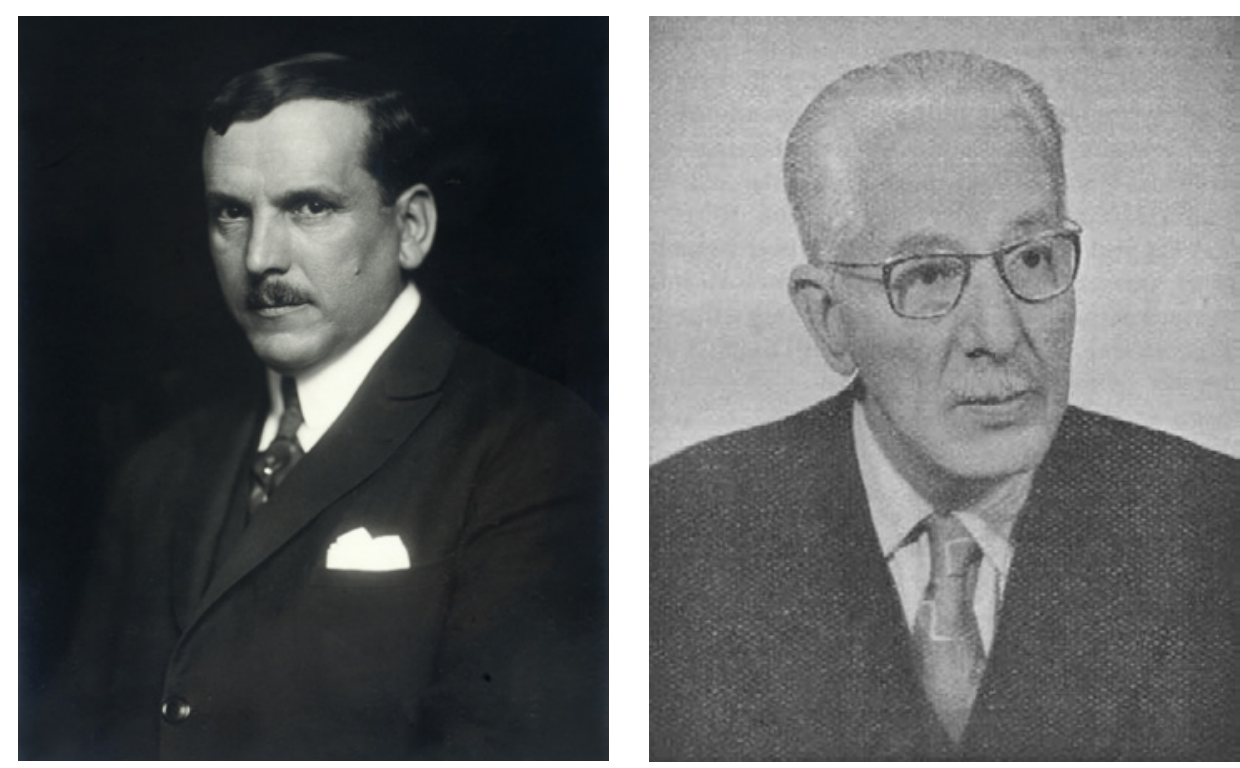

Figuras 1 y 2.

Enrique Romero de Torres y Samuel de los Santos Gener, comisarios provinciales de Córdoba y directores de los Museos de Bellas Artes y Arqueológico (Galería Witcomb de Buenos Aires, 1922, Museo de Bellas Artes de Córdoba; Boletín de la Real Academia de Córdoba 78: 3, 1957).

hasta su jubilación voluntaria en 1941 (Palencia 2006). Enrique sería el gran continuador de la obra de Romero Barros, tanto al frente del Museo como de la CPM, institución de la que sería nombrado secretario tras el fallecimiento de su progenitor. De su constante asistencia y participación en las actividades de la misma dan fe tanto las actas de dicha institución como la restante documentación conservada en los legajos de la CPM y del archivo Romero de Torres.

$\mathrm{Su}$ acercamiento a la Arqueología se inicia con el descubrimiento, en 1897, de los capiteles árabes de la casa solariega, hoy desaparecida, conocida como del Gran Capitán, una intervención que impidió la venta y salida del país de las piezas, donadas al Estado gracias a su mediación por el propietario del inmueble y finalmente depositadas en el Museo Arqueológico Nacional (Bugella 2018). De su labor como arqueólogo resulta imprescindible recordar las excavaciones llevadas a cabo en las áreas funerarias de la Puerta de Sevilla y el Camino Viejo de Almodóvar durante la década de los treinta, iniciadas estas últimas a raíz del hallazgo casual, en 1931, de la tumba monumental hoy emplazada junto a la Puerta de Sevilla (fig. 3), y que supusieron el descubrimiento y estudio de la primera de las necrópolis romanas documentadas en Córdoba, la occidental, paralela al trazado seguido por la Via Augusta en dirección a Hispalis (Romero 1941; Santos 1955: 8-9). Tras el Alzamiento, Enrique Romero de Torres fue ratificado como director del Museo de Bellas Artes y nombrado jefe interino de los servicios jurídicos de la sección de Bellas Artes y de Falange, convirtiéndose en «figura máxima del arte de la nueva situación política cordobesa» (Palencia 2006: 100).

En los años siguientes, Romero de Torres formaría parte de todas las instituciones creadas por el nuevo Estado, a nivel local y provincial, para la salvaguarda y control del patrimonio histórico-artístico. Junto a la antigua CPM, que prolongaría su existencia y actividades hasta el final del régimen franquista, formó parte en primer lugar de la Subcomisión de la Junta Conservadora del Tesoro Artístico, que funcionó en Córdoba como delegada de la Junta creada por Queipo de Llano en Sevilla. Tras la desaparición de esta, en febrero de 1937, sus funciones fueron asumidas por la Junta de Cultura Histórica y del Tesoro Artístico de Córdoba, de la que Enrique fue presidente (Palencia 2006: 101-102). Disuelta esta última por el citado decreto de 22 de abril de 1938, fue nombrado apoderado del SDPAN y comisario provincial de la CGEA en Córdoba. Si bien su carnet de comisario fue expedido, con el $\mathrm{n}^{\circ} 14$, en 1944, figura en el mismo como fecha de nombramiento el 14 de mayo de 1941 (Archivo Provincial de Córdoba, Legado Romero de Torres, caja 25; en adelante LRT, Cxx). Dicho nombramiento se produjo cuando, en virtud de la citada OM de 30 de abril de 1941, la CGEA elevó a la DGBA un listado en el que Santa-Olalla incluyó a quienes, como Enrique Romero de Torres, habían ejercido el cargo de comisario desde 1939 (Gracia 2009: 244-248).

Se ha acusado, no sin razón, a Santa-Olalla de evitar en los nombramientos de comisarios a los profesionales de la disciplina, en especial a sus colegas universitarios, 
Figura 3.

Tumba del Camino Viejo de

Almodóvar, reconstruida junto a la Puerta de Sevilla

(archivo de la autora).

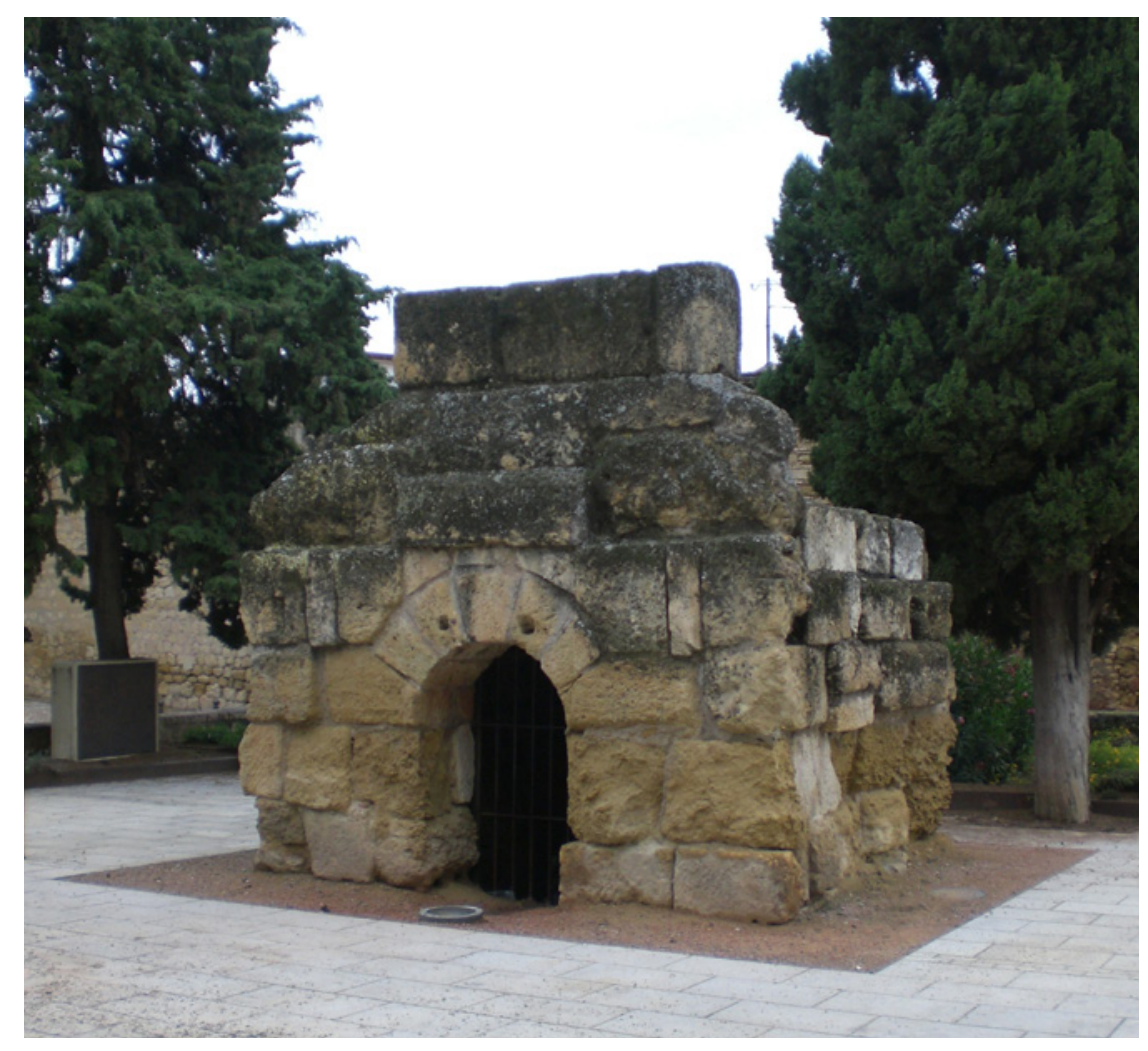

promoviendo en su lugar a

"amantes de la Arqueología" sin la suficiente formación para el trabajo arqueológico (Castelo et al. 1997: 577; Díaz-Andreu y Ramírez 2001: 331; Gracia 2009: 247). No es el caso de Romero de Torres, poseedor de una amplia experiencia tanto de excavación como en la búsqueda y recuperación de los numerosos hallazgos casuales, cuyo destino casi inevitable era perderse en el mercado anticuario. Sí resulta más ambigua su figura si tenemos en cuenta que paralelamente formó una colección privada de antigüedades, hoy conservada en el Museo de Bellas Artes de Córdoba. En teoría, los coleccionistas en activo no podían ser comisarios, pero en la práctica se realizaron numerosas excepciones (DíazAndreu y Ramírez 2001: 335).

Clave en el nombramiento de Romero de Torres fue, muy probablemente, el previo conocimiento personal que de él poseía Santa-Olalla, y que debía remontarse, aunque no hemos podido documentarlo, a las campañas de excavación realizadas entre 1933 y 1935 por Santa-Olalla, junto con Joaquín $\mathrm{M}^{\mathrm{a}}$ de Navascués, en el yacimiento ibérico de Fuente Tójar y de las que lamentablemente solo nos queda el testimonio oral de los vecinos que trabajaron en ellas y el informe presentado al MAN, al que no llegaron la mayor parte de los materiales recuperados (Vaquerizo et al. 1992: 177; Leiva 2007: 307-311). La documentación conservada en los legajos del archivo Romero de Torres no permite rastrear los comienzos de una cortés amistad, que resulta tan evidente en la correspondencia mantenida como la escasa tendencia de Enrique a plegarse a las exigencias del comisario general (vid. infra). A diferencia de lo que suele reprocharse a Santa-Olalla, no debió ser la ductilidad el rasgo de carácter que propició su nombramiento.

\subsection{Actividad arqueológica de la CGEA en Córdoba}

La documentación sobre la CGEA de Córdoba conservada en el archivo Romero de Torres se encuentra ordenada por años, comprendiendo el periodo 1941-46 en que Enrique fue comisario provincial. Dentro de la misma hemos realizado una selección de las actuaciones que nos han parecido más reveladoras, no tanto de la vida interna de la institución, como de la situación del patrimonio arqueológico cordobés durante la que sin duda fue la etapa más difícil de la posguerra. No es 
de extrañar que una constante que limitó su actividad y eficacia fuera la falta de medios, puesta de manifiesto en un temprano oficio del secretario de la CGEA, Carlos Alonso del Real y de Ramos, inquiriendo sobre ciertos restos arqueológicos de época islámica aparecidos en la localidad de Fuente Ovejuna, y respondido por Enrique Romero de Torres con que le era imposible inspeccionarlos, pues la Comisaría Provincial «no cuenta con subvención de ninguna clase para hacer viajes de inspección (...) teniendo en cuenta lo costoso y difícil que resultan las comunicaciones actuales por falta de gasolina» (oficio de 17-1-1941 y respuesta de Romero de Torres, LRT, C25/40). Informa asimismo Romero de Torres en la Memoria del año 1940 (LRT, C25/40) de la aparición de mosaicos romanos en las localidades de Hornachuelos y Fernán Núñez, que no le es posible inspeccionar personalmente. La situación no parece mejorar en años posteriores, pues en 1943 ruega Enrique a la CGEA se abonen a los comisarios los desplazamientos a Madrid y a los municipios de la propia provincia (oficio de 16-12-1943, LRT, C25/42).

La falta de medios intentaría paliarse con la concesión, por parte de la DGBA, del acceso gratuito de los comisarios a museos y monumentos, junto a la creación de un servicio de biblioteca circulante de publicaciones científicas. Hay que recordar que el cargo de comisario, como el de miembro de la CMP y el de apoderado del SDPAN, era una distinción no remunerada, que exigía no poco tiempo y esfuerzo de su titular. Escasos recursos y amateurismo aparecen combinados en la singular propuesta de Alonso del Real, ofreciendo la colaboración de dos instructores del Frente de Juventudes por si en los campamentos del mismo se pudieran realizar labores arqueológicas (oficio de 30-6-1943, LRT, C25/42).

Una segunda constante de la institución fue el "totalitarismo" desplegado por el comisario general, deseoso de estar informado de los más menudos pormenores de cualquier actividad vinculada a la Arqueología que tuviera lugar en la provincia. Exige al respecto Santa-Olalla recortes de la prensa provincial con noticias de hallazgos arqueológicos, la relación del material adquirido para excavaciones subvencionadas por el Estado con anterioridad a la Guerra Civil (oficios de 22-4-1941 y 29-3-1943, LRT, C25/40 y 42), o información sobre los guardas de los monumentos, remitiéndole Enrique los nombres y haberes de los conserjes (telegrama de Santa-Olalla, s/f, y oficio de Romero de Torres de 15-9-1941, LRT, C25/40). Cuestiones nimias que, en este último caso, nos permiten sin embargo entrever la precaria situación en que se encontraba el patrimonio arqueológico: la petición de Santa-Olalla de información sobre el guarda de Medina Azahara encuentra como respuesta el deseo de Rafael Castejón de recuperar el dinero abonado al mismo, cuyo jornal había estado pagando durante cinco años de su bolsillo (carta de Castejón a Romero de Torres de 23-12-1942, LRT, C25/41).

\subsection{Excavaciones}

De acuerdo con la Orden de 9 de marzo de 1939, correspondía a la CGEA el control de las excavaciones arqueológicas, que sin embargo debían ser autorizadas por la DGBA, de la que dependía. Las Comisarías Provinciales debían además presentarle memorias anuales, en las que se comunicaran las excavaciones realizadas, los hallazgos casuales, posibles destrucciones, ingresos de piezas en los museos o en colecciones privadas, e incluso noticias de prensa referidas al patrimonio arqueológico (oficio de Santa-Olalla de 18-9-1940, LRT, C25/39). En el archivo Romero de Torres únicamente se conserva la correspondiente a 1940, en la que Enrique da cuenta de que durante dicho año no se habían realizado excavaciones oficiales, informando pormenorizadamente de los numerosos hallazgos casuales producidos en la provincia.

\subsubsection{Medina Azahara}

De las subvenciones para proyectos de excavación concedidas por la CGEA, destaca M. Díaz-Andreu que, por lo que a Andalucía se refiere, Córdoba queda en segundo lugar después de Málaga en cuanto a la cuantía de las mismas (Díaz-Andreu 2011: 48). No son las modestas cantidades percibidas por Samuel de los Santos Gener, 8.000 pesetas entre 1949 y 1951, sino el yacimiento de Medina Azahara, denominación esta más común en la época que la de Madinat al-Zahra, el causante de tan destacada posición. En 1942 se reanudan en la ciudad-palacio los trabajos interrumpidos por la Guerra Civil, a los que la Junta Superior de Excavaciones y Antigüedades había destinado un $22,30 \%$ de su presupuesto total para el periodo 1915-1936, la mayor inversión de España en excavaciones arqueológicas; una excepción si consideramos que junto con la Alhambra, el otro yacimiento señero de la Arqueología medieval islámica, el interés continuaba volcado hacia la Arqueología hispanorromana, con Itálica en el caso de Andalucía como yacimiento 
estrella (Beltrán 2011: 35). Cifra M. Díaz-Andreu los motivos que explican dotaciones tan generosas en una política iniciada durante la dictadura de Primo de Rivera, y no alterada ni por la República ni durante el franquismo, de primar, antes que la investigación, la excavación y reconstrucción de monumentos visitables, con atractivo turístico, como Medina Azahara, Itálica o Mérida (Díaz-Andreu 2003: 45-46). Entre 1939 y 1955, aun suponiendo los proyectos de Martínez Santa-Olalla un 18,40\% del presupuesto estatal para excavaciones, Medina Azahara recibió un porcentaje del 5,1\% del total de las subvenciones, solo por detrás de Mérida, con un 5,99\% (Díaz-Andreu 2011: 48).

La excavación en Medina Azahara fue iniciada en 1911 por el arquitecto Ricardo Velázquez Bosco, quien desde 1907 trabajaba en la restauración de la mezquita-catedral de Córdoba. Tras su fallecimiento en 1923, producido apenas unos días después de que el yacimiento fuera declarado Monumento Nacional, la Junta Superior de Excavaciones designó para continuar los trabajos una comisión delegado-directora integrada por miembros de la CPM de Córdoba, de la que formaron parte, junto a su presidente Rafael Jiménez Amigo y los vocales Ezequiel Ruiz Martínez y Rafael Castejón (académicos de Bellas Artes y de la Historia, respectivamente), Joaquín $\mathrm{M}^{\mathrm{a}}$ de Navascués, en aquel momento director del Museo Arqueológico de Córdoba, y el arquitecto Félix Hernández, quien iniciaría su larga dedicación al yacimiento con el levantamiento del plano general de las ruinas ( $\mathrm{Ji}$ ménez 1924; Castejón 1925). Tras el largo paréntesis impuesto por la Guerra Civil, en 1943 se reanudan unas excavaciones para las que son nombrados comisarios-directores Félix Hernández, Rafael Castejón y Emilio Camps Cazorla, a la sazón secretario del Museo Arqueológico Nacional (oficio de Alonso del Real de 30-6-1943, LRT, C25/42). Este último nombramiento fue decidido directamente por el marqués de Lozoya, en contra de la opinión de SantaOlalla, con el argumento de la necesaria presencia de Manuel Gómez-Moreno, o al menos un representante suyo, en el yacimiento, si bien sería el arquitecto quien asumiría la dirección real del mismo (Gracia 2009: 244-248).

La excavación inicial de 1943 retomó los trabajos interrumpidos en 1936 en la zona de la muralla norte y la terraza superior (figs. 4 y 5). La memoria de excavación, redactada por R. Castejón, fue publicada en los Informes y Memorias de la Comisaría General de Excavaciones (Castejón 1945a), principal medio de difusión de los trabajos de la CGEA, siendo la mayor parte del material mueble descubierto remitido al Museo Arqueológico Nacional (Archivo del Museo Arqueológico Nacional, en adelante Archivo MAN, 1943/11). El lote, compuesto por treinta y siete piezas cerámicas y dos de vidrio, fue cedido como un depósito temporal que con el tiempo parece haberse vuelto definitivo. Tanto la actual situación del Museo Arqueológico cordobés como la inauguración en el año 2009 del Museo de Madinat al-Zahra quizá debieran hacer reconsiderar un destino en aquel momento casi inevitable, habida cuenta de que el Museo Arqueológico Provincial carecía de espacio e instalaciones adecuadas, encontrándose instalado en régimen de alquiler en la conocida como Casa Mudéjar, en la calle hoy denominada Samuel de los Santos Gener. La compra de la que es aún hoy su sede definitiva, el palacio de los Páez de Castillejo, tuvo lugar durante la época que nos ocupa, en 1942, pero la instalación en el mismo se retrasaría hasta 1960 (Santos 1950: 9-14; Garriguet 2009/10: 1213). Por otra parte, los locales habilitados en el propio yacimiento de Medina Azahara, germen del museo de yacimiento soñado por su primer excavador (Velázquez 1923: 23), son descritos por R. Castejón como «naves y cobertizos» (Castejón 1945a: 59). En los años siguientes, además, antes que el estudio del material mueble sería la reconstrucción del gran salón basilical conocido como Salón Rico, descubierto en 1944, el que marcaría el ritmo de las excavaciones (Vallejo 2010: 40-43 6).

\subsubsection{Excavaciones anteriores a la Guerra Civil}

El afán controlador de la CGEA se extiende como hemos comprobado al periodo anterior a la Guerra Civil. Recordemos que la citada Orden de 21 de abril de 1941 obligaba a presentar memorias de las realizadas con anterioridad al conflicto. Junto a la solicitud inicial de remitir un inventario del material adquirido para excavaciones con cargo a fondos del Estado, aún se reclama información sobre las realizadas antes del Alzamiento en fecha tan relativamente tardía como 1943 (oficios de 22-4-1941 y 31-5-1943, LRT, C25/40 y 42). Por lo que a excavaciones concretas ser refiere, inquiere Santa-Olalla sobre las realizadas por el ingeniero de montes Manuel Aulló en 1923, en el área dolménica de Villanueva de Córdoba (Au1ló 1925; Carbonell 1927). Desconociendo Romero de Torres el paradero del ingeniero, únicamente informa de que, según le transmite Santos Gener, los objetos 


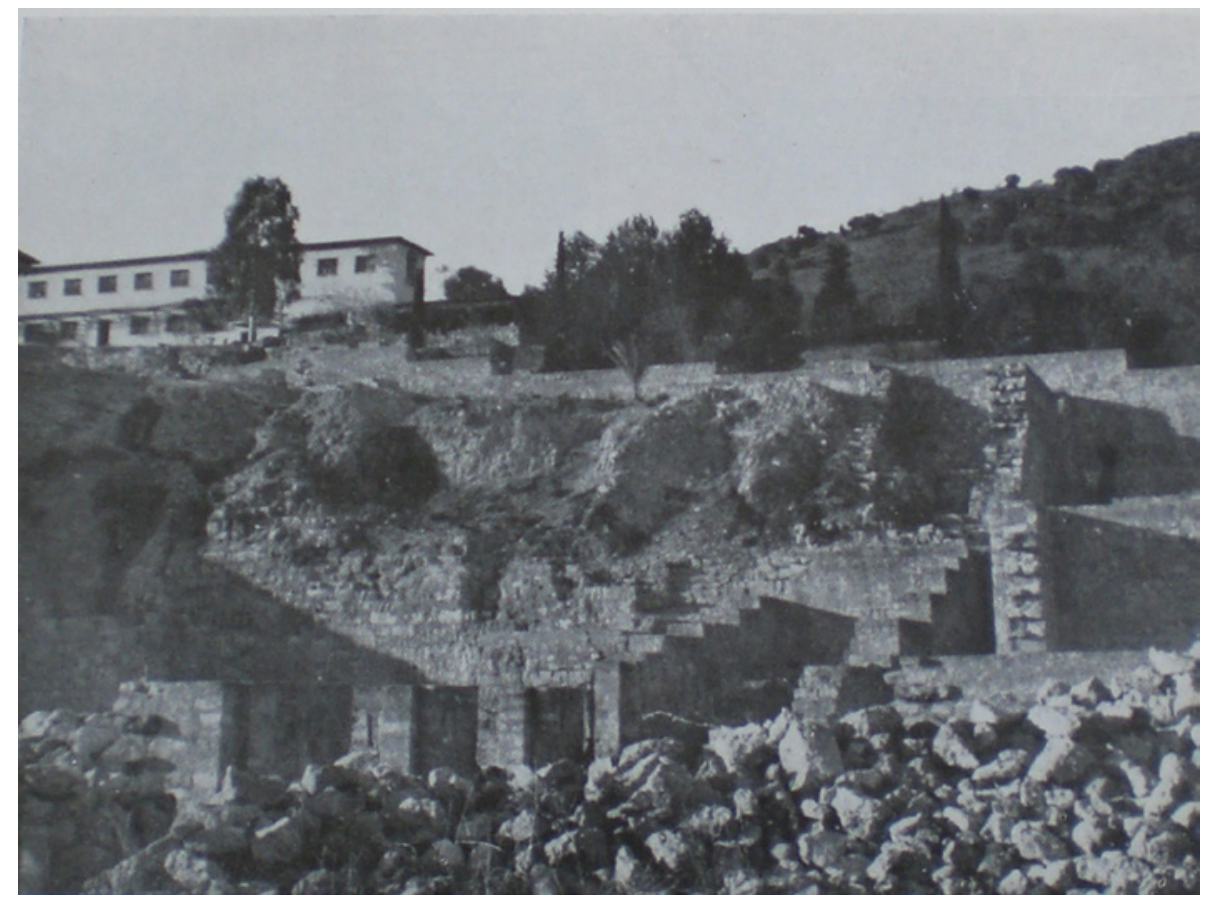

Figura 4. Vista parcial de la muralla norte y de los locales del museo de Medina Azahara (Castejón 1945a: Lám. I). encontrados, vasijas, un cuchillo de sílex y puntas de flecha microlíticas recogidas en diversos enterramientos, no ingresaron en el Museo Arqueológico de Córdoba (oficio de 25-4-1941 y respuesta de Romero de Torres, LRT, C25/40).

Se interesa asimismo Alonso del Real (oficio de 262-1940 y respuesta de Romero de Torres, LRT, C25/39) por el paradero de dos esculturas ibéricas aparecidas en la localidad de La Rambla y depositadas en el disuelto Instituto de Bachillerato de la localidad, solicitando su envío al Museo Arqueológico Provincial. Las esculturas, un caballo de piedra y una cabeza de león, procedían de una excavación realizada años atrás en el paraje conocido como Las Cabezas del Rey por uno de los profesores de dicho Instituto, Enrique Careaga. No hemos encontrado publicación alguna de las mismas ni en las Memorias de la Junta Superior de Excavaciones y Antigüedades ni en el Boletín de la Real Academia de Córdoba, precisando únicamente Santos Gener en su Guía del Museo que en el lugar "afloraban ruinas antiguas, entre restos de muros y cerámica ibérica» (Santos 1950: 45). Sobre el destino de las esculturas, informa Romero de Torres a la CGEA de las gestiones realizadas ante el alcalde de la localidad y del compromiso del mismo de remitir las piezas al Museo, confirmando la memoria de 1940 su entrega al mismo (LRT, C25/40 y Museo Arqueológico y Etnológico de Córdoba, en adelante MAECO, DO000041/1 y DO000041/2).
Con respecto a las excavaciones realizadas en el área funeraria de la Puerta de Almodóvar durante los años treinta, informa Romero de Torres (oficio de 6-81939, LRT, C25/38), en cumplimiento de la citada Orden de 3 de abril de 1939, del depósito en el Museo Arqueológico Provincial de todas las piezas encontradas en las excavaciones por él dirigidas entre 1931 y 1935, así como del envío a la Junta Superior de Excavaciones de las cuentas de las mismas. Reconoce sin embargo que le había sido imposible remitir las memorias, pues dos de las necrópolis excavadas poseían características a su juicio tan extrañas, que requerían un estudio en profundidad, pudiendo finalmente confirmar de una de ellas que se trataba del fonsario de los judíos. Refiere asimismo que el trabajo exigido por sus responsabilidades oficiales, unido a la falta de material fotográfico para copiar los clichés de las excavaciones, le habría impedido finalizarlas. No consta en la documentación si finalmente llegó a enviar las memorias de excavación, pues en los meses siguientes demanda sucesivos aplazamientos, concedidos por la CGEA, motivados por la falta de material fotográfico. Deja finalmente constancia de su conclusión en julio de 1940, si bien continuaban careciendo de material gráfico, sin el cual no consideraba posible que pudieran publicarse (oficios de Romero de Torres de 6-91939 y 20-7-1940, y de Alonso del Real de 5-12-1939, LRT, C25/38 y 39). 


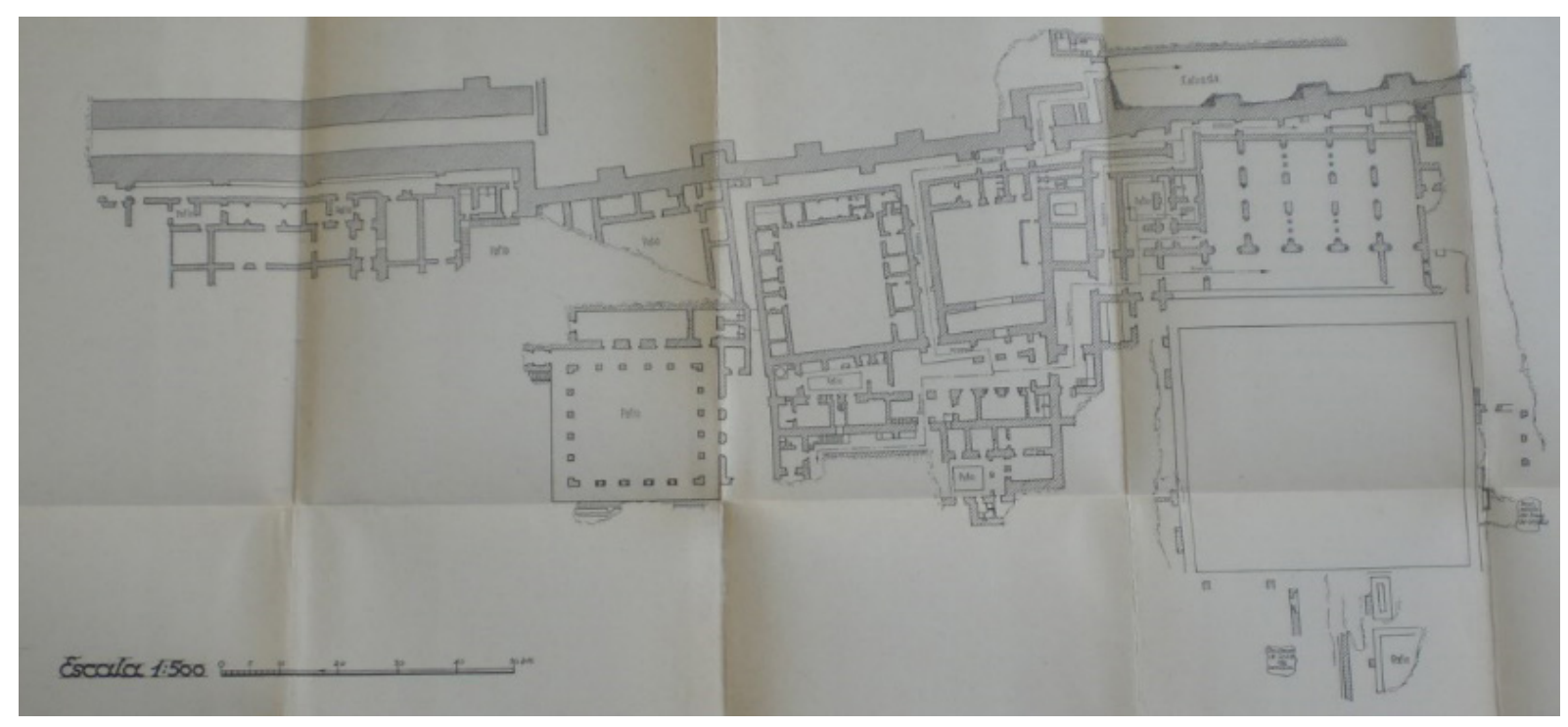

Figura 5. Plano general de lo excavado en Medina Azahara hasta 1943 (Castejón 1945a: s/p).

\subsection{Gestión de los hallazgos casuales}

Los hallazgos casuales constituyen la parte más rica de la documentación conservada en el archivo Romero de Torres y su seguimiento constituyó la principal actividad del Comisario Provincial; una labor que ya llevaba a cabo con anterioridad a su nombramiento, como miembro de la CPM, y de la que hemos tenido ocasión de documentar su preocupación, e infructuosa lucha, contra el tráfico ilegal de piezas arqueológicas (Bugella 2016a). Recordemos que la Ley de Excavaciones de 1911 permitía conservar la propiedad a los poseedores de antigüedades en el momento de promulgación de la Ley, concediendo al Estado únicamente un derecho de tanteo y retracto si se producía su venta (art. 9). El Título III de la Ley de Patrimonio de 1933 (arts. 4154), dedicado a los objetos muebles, exigía además solicitar autorización para su venta a la Junta Superior del Tesoro Artístico si el valor de las piezas superaba las 50.000 pesetas (arts. 41 y 52), organismo que también era responsable de autorizar su posible exportación (art. 44).

Pese a las modestas previsiones legales reseñadas, la falta de sensibilidad ciudadana y la carencia de medios económicos de CPM y Museo Arqueológico convertían en una constante los robos y la venta clandestina de obras de arte (Bugella 2017b: 257), situación que, lejos de mejorar durante la posguerra, se agrava incluso por la penuria económica de la época. Santos Gener da cuenta en el Registro de hallazgos arqueológicos de las numerosas piezas perdidas por la imposibilidad de Estado de adquirirlas, mientras que en su Memoria de las Excavaciones del Plan Nacional realizadas en Córdoba resume las condiciones de trabajo en las que se desenvolvía la inspección del «gran número de ruinas que se descubren fortuitamente sin previo aviso, $\mathrm{y}$ cuyo control hemos de realizar a fuerza de paseos en busca de obras», unas obras cada día más numerosas en una ciudad que «debido al incremento actual de su número de habitantes, se renueva y extiende en recientes trabajos de urbanización» (Santos 1955: 95).

Lamenta asimismo Santos Gener la ambigüedad del art. 6 de la Ley de 1911, que permitía que los hallazgos fortuitos fueran «retenidos por el propietario del terreno o llevados a una colección particular, en igualdad de derecho que los Museos oficiales de Arqueología» (Santos 1955: 95-96). Realmente, el citado art. 6 menciona únicamente «objetos artísticos ó arqueológicos procedentes de excavaciones» y no hallazgos casuales, sobre los que el art. 5 de la Ley de Excavaciones es tajante: serían propiedad del Estado, a partir de su promulgación, las antigüedades «descubiertas casualmente en el subsuelo o encontradas al demoler antiguos edificios» (art. 5), debiendo entregarse la mitad de su valor al descubridor y la otra mitad al dueño del terreno. A pesar de ello, en toda la documentación que hemos manejado para este u otros trabajos jamás hemos encontrado que Museo, Comisaría Provincial, CPM o cualquier otro organismo público se atrevieran a aplicar con rigor el citado artículo, como tampoco el posterior art. 40 de la Ley de 1933, que ofrecía la posibilidad de optar entre la entrega de las piezas al Estado, con 


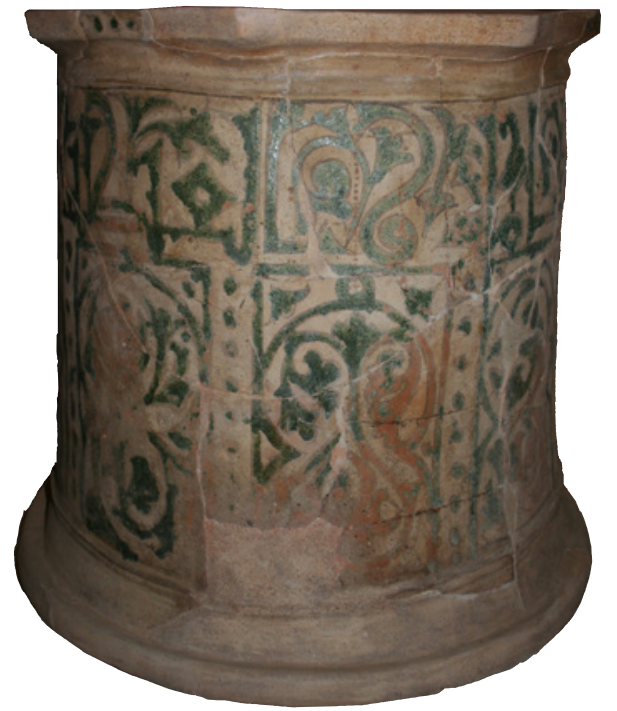

Figura 6. Brocal de pozo donado al Museo Arqueológico por mediación de E. Romero de Torres (MAECO, $\mathrm{n}^{\circ}$ registro CE007515).

indemnización, o el disfrute de lo hallado al descubridor, a condición de que se comprometiera a permitir su estudio. Quienes se encontraban al frente de dichas instituciones intentaron, más que indemnizar, adquirir a "precio de mercado" las piezas que se ofrecían, o bien apelar a la generosidad de sus poseedores. De no haber sido así, es más que probable que nunca hubieran tenido noticia de su existencia, pues quienes las encontraron habrían procedido directamente a su ocultación y venta en el mercado anticuario.

Claro ejemplo de la actitud descrita lo constituye el caso de un hallazgo del que demandó información la CGEA, pese a haberse producido en la ya entonces remota fecha de 1930. Se trata de las piezas escultóricas, entre las que destaca la figura en mármol de una deidad, probablemente Diana Cazadora, encontradas en la finca conocida como Casilla de la Lámpara, sita en el término municipal de Montilla. Enrique Romero de Torres había formado parte de la comisión tasadora nombrada por la DGBA, que valoró el conjunto «en la cantidad de DOS MIL pesetas en vista de su importancia arqueológica» (MAECO, CE006424; acta de 20-41932, LRT, C24/28). Inquiere el Comisario General si las piezas se encontraban aún en manos del propietario, respondiendo Romero de Torres que habían sido tasadas y adquiridas por el Estado, siendo depositadas en el Museo Arqueológico Provincial (oficio de 26-91940, y respuesta de Romero de Torres, LRT, C25/39).
El asunto muestra la claudicación del Estado ante los intereses particulares: pese a que, por tratarse de un hallazgo fortuito, es el legítimo propietario de las piezas, la abultada cifra en que son tasadas supone más una adquisición que la debida indemnización a los dueños de la finca. Ofrece asimismo un buen ejemplo de la "causa general" que parece querer abrir Santa-Olalla a la actividad arqueológica desarrollada en España con anterioridad a la Guerra Civil, y cuya más remota referencia hemos rastreado en 1925, fecha en la que el Comisario General afirma haber leído en prensa la aparición de una estela funeraria ibérica hallada a unos dos kilómetros al oeste de Córdoba, en los terrenos de la Sociedad Española de Construcciones Electro Mecánicas, sobre la que inquiere noticias (MAECO, CE004348; carta de Santa-Olalla de 10-10-1940, LRT, C25/39). De nuevo, la pieza descansaba desde hacía varios lustros en los locales del Museo Arqueológico Provincial, tras haber sido donada por la empresa al mismo gracias la intervención de la CPM (Bugella 2017b: 258).

La memoria de 1940 deja constancia de hallazgos casuales que, como un busto del dios Marte procedente de la localidad de Puente Genil, o una moneda árabe de oro encontrada en Nueva Carteya, el Museo Arqueológico Provincial simplemente no puede adquirirlos. Describe las circunstancias de la frustrada transacción de esta última Santos Gener, a quien le es ofrecida por su entonces poseedor, Francisco Cuevas, una «moneda de oro bilingüe árabe acuñada en Alandalus, con una estrella en el centro y la inscripción N. FERITVSNOVM IN SPANIA... al reverso en árabe. Es moneda del s. I de la Hégira. Pide por ella 200 pesetas, pues no es suya, sino de otro del pueblo» (Santos 1958: 86). En ocasiones, los propietarios se desprenden generosamente de las piezas encontradas, como los restos arquitectónicos aparecidos en la conocida como Casa de las Pavas, cuyo dueño, Luciano Gómez, dona al Museo. Precisa Santos Gener que se trata de piezas aparecidas durante unas reformas realizadas para dividir en viviendas la casa solariega, en la que «se halló una columna árabe con sus tres elementos, basa, fuste y capitel (...) de gran interés por ser su decoración de tipo diferente a los corrientes en Córdoba» (MAECO, CE007323; Santos 1958: 85-86).

Enrique Romero de Torres actúa como mediador en la entrega de numerosos hallazgos, como las mencionadas esculturas de La Rambla; un sarcófago de mármol aparecido durante la construcción de un garaje en los Campos de Vista Alegre, situados en el entorno de la necrópolis del Camino Viejo de Almodóvar, y donado al Museo «por gestión de D. Enrique Romero de Torres» 
(MAECO, CE007335; Santos 1958: 90); o un brocal cerámico de pozo almohade (MAECO, CE007515; fig. 6), decorado con motivos vegetales e inscripciones, «el cual fue hallado al hacer unos de los pozos para el alcantarillado nuevo que se construye en terrenos de la Huerta Cardosa» (Santos 1958: 102).

Por lo que a los hallazgos arqueológicos producidos durante la realización de obras públicas se refiere, un oficio de Alonso del Real, comunicando a Romero de Torres que se ha cursado a Ayuntamiento y Diputación Provincial la orden de informar sobre los mismos a la Comisaría Provincial, recibe como respuesta que ambas instituciones no informan habitualmente a Comisaría, ni siquiera cuando se trata de obras de la entidad de un nuevo hospital costeado por la Diputación (oficio de 10-10-1942 y respuesta de Romero de Torres, LRT, C25/41). La situación obviamente no mejora si nos alejamos de la capital. Informa Romero de Torres a la CGEA del cumplimiento en la propia ciudad de Córdoba de su circular $n^{\circ} 8$, referida a los hallazgos casuales, pero no así en los municipios de la provincia, donde sistemáticamente se roban o destrozan (circular de 7-7-1945 y oficio de Romero de Torres, LRT, C25/44). Ejemplo de ello son los restos aparecidos en el término municipal de Monturque, durante las obras realizadas a la altura del $\mathrm{km} 44$ de la carretera CórdobaMálaga. Las noticias llegan a la Comisión Provincial de Excavaciones (sic) a través de un particular, Carlos Santos Álvarez, procurador de los tribunales en la vecina localidad de Aguilar de la Frontera, quien afirma que «desde hace unos diez días se vienen encontrando gran cantidad de monedas romanas de valía, ánforas, sepulturas y otros restos de gran importancia arqueológica, que desaparecen y se pierden a los pocos momentos del hallazgo» (carta de Carlos Santos Álvarez a Romero de Torres de 20-4-1945).

Si bien el citado informador había recabado la ayuda de las autoridades municipales, solicitaba en el mismo escrito ser nombrado comisario local, cargo que consideraba le daría la suficiente autoridad como para recuperar las piezas encontradas y depositarlas en el museo local, del que afirmaba ser director. Responde Romero de Torres que informaría de la situación al gobernador civil $\mathrm{y}$, por lo que se refiere al nombramiento solicitado, que no le correspondía a él efectuarlo, admitiendo sin embargo que Carlos Santos lo representara oficiosamente en la localidad. En oficios posteriores, la Comisaría Provincial demanda a Diputación y al ingeniero-jefe de Obras Públicas en la provincia que los restos aparecidos con motivo de obras en las carreteras fueran depositados en los Ayuntamientos o entregados a la Guardia Civil (respuesta de Romero de Torres a Carlos Santos y oficios de 22 y 27-9-1945, LRT, C25/44). A pesar de ello, no volvemos a tener noticias de hallazgos en las mencionadas obras ni por la correspondencia de Romero de Torres ni en el Registro de hallazgos de Santos Gener, quien en este caso únicamente refiere la aparición de "gran cantidad de cadáveres enterrados hace muchos años, quizá como resultado de la Batalla de Poley, entre las tropas de Abderramán III con D. Pedro de Castilla», breve mención de un caso que parece no haber seguido personalmente (Santos 1958: 136-137). Queda en cualquier modo manifiesta la desidia de las autoridades locales y provinciales, a las que la CGEA ya reitera su obligación de comunicar los hallazgos producidos en las obras, visto que los informes del Comisario Provincial «no ponen de manifiesto un particular interés por parte de las autoridades dependientes de V. I. en la aplicación de dichas disposiciones» (oficios de Alonso del Real al Ayuntamiento de Córdoba y a la Diputación Provincial de 238-1943, LRT, C25/42).

Ejemplo de hallazgo casual y a la vez de escasa colaboración de las autoridades en la protección del patrimonio arqueológico son también los baños califales de la calle Pescadería, descubiertos por Enrique Romero de Torres durante su etapa de comisario provincial y en cuyo examen no nos detendremos, por haber sido su azaroso estudio y conservación objeto de una publicación anterior (Bugella 2016b). Seleccionamos por ello en los apartados siguientes las circunstancias del hallazgo de piezas especialmente relevantes, por su entidad o por la luz que arrojan sobre la actividad de la Comisaría Provincial y sobre los factores que provocaron el abandono de la misma por quien fue su primer comisario.

\subsubsection{Necrópolis romana de la calle Diario de Córdoba}

Las obras realizadas en el solar de la calle Diario de Córdoba $n^{\circ} 19$, propiedad de Rafael Suárez de la Riva, exhumaron una necrópolis situada en el entorno del lienzo oriental de la urbe romana y la Via Augusta, que se adentraba en la ciudad a través de la que en la Edad Moderna sería conocida como Puerta del Hierro. El descubrimiento permitió confirmar la existencia de una segunda área de enterramientos en el extremo opuesto a la ya excavada por Romero de Torres en los años treinta, junto a la Puerta de Almodóvar. Recoge la memoria de 1940 la aparición de un primer sarcófago de plomo romano, comunicando asimismo sendos oficios 


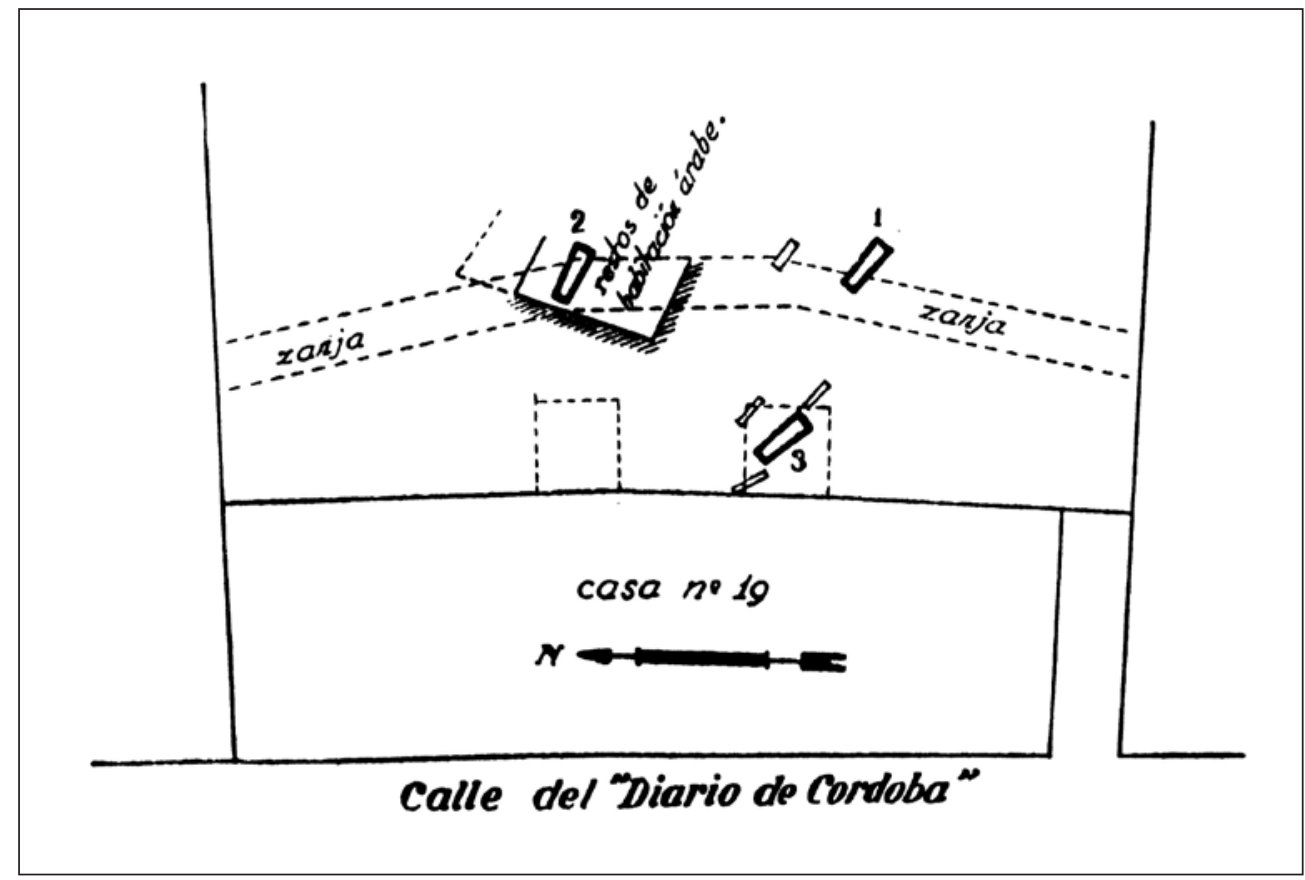

Figura 7.

Croquis con la localización de los hallazgos de c/ Diario Córdoba $\mathrm{n}^{\circ} 19$ (Santos 1940/41: 438).

de Santos Gener y de Romero de Torres la donación al Museo Arqueológico Provincial tanto de este como de un segundo ejemplar, encontrado posteriormente junto con otros restos de carácter funerario (MAECO, DO000074 y CE007336; oficio de Romero de Torres de 23-1-1941, LRT, C25/40). El área de necrópolis y las piezas fueron publicadas por Santos Gener (fig. 7), quien pudo documentar, bajo los restos de estructuras de habitación de época islámica, hasta ocho sepulturas de inhumación, en las que se hallaron los sarcófagos mencionados, decorados con bandas de motivos vegetales y de cacería impresas en sus tapas. Por la tipología de los enterramientos y una moneda de Teodosio, aparecida al mismo nivel que los sepulcros, fueron datados a finales del siglo IV (Santos 1940/41; Martín 2002).

La noticia de la aparición de los sarcófagos fue publicada en el diario nacional Arriba, motivando la inmediata consulta de Alonso del Real al comisario provincial sobre si se trataba de alguna de sus actividades. Responde Romero de Torres que lo publicado en Arriba reproducía la información ofrecida por Santos Gener en el diario cordobés $A z u l$, con fecha 6 y 12 de febrero de 1941, en la que describía el lugar y tipología de los hallazgos, adjuntando copia de la noticia de la aparición de un tercer sarcófago en el mismo lugar que los anteriores (oficio de 7-2-1941 y respuesta de Romero de Torres, LRT, C25/40). Este último fue vendido por Suárez de la Riva al Museo Arqueológico
Nacional (en adelante MAN), al parecer por 2.500 pesetas. En la decisión del propietario quizá pudo pesar que en $A z u l$ apareciera por error como donante de los dos primeros sarcófagos el arquitecto Félix Hernández, o simplemente el valor crematístico de la pieza, cuya tapa, decorada con leones y jabalíes, es la mejor conservada (MAN, 38655; Archivo MAN, 1949/13; carta de Santos Gener a Romero de Torres de 23-1-1941, LRT, C25/40). Nos encontramos de nuevo ante un ejemplo de adquisición por parte del Estado, más que de indemnización al propietario del terreno, que ilustra asimismo una constante en la conducta tanto de particulares como de marchantes profesionales, como es la de escoger como interlocutor para sus transacciones al MAN, mejor provisto de recursos que el depauperado Museo cordobés (Papí y Balmaseda 2008).

\subsubsection{Ciervo califal de bronce del Museo Arqueológico Nacional}

El proceder de Suárez de la Riva se reproduce en el que, junto con la pila de Alamiriya (vid. infra) quizá sea uno de los hallazgos más relevantes del periodo, un ciervo califal de bronce, muy semejante al conservado en el Museo Arqueológico Provincial (Archivo MAN, 1943/41/1; MAECO, CE000500; Camps 1943). Aparecido en la finca Huerta de la Capilla, situada al oeste 
de la ciudad y propiedad del ingeniero Federico de las Morenas Cabrera, «fue ocultado por su propietario bastante tiempo y llevado por su hijo a Madrid, donde fue presentado a D. Blas Taracena Aguirre, Director del Museo Arqueológico Nacional, quien gestiona del propietario lo ceda a aquel museo gratuitamente, por cuya cesión promete el Ministerio compensar al Museo Arqueológico de Córdoba» (Santos 1958: 85; fig. 8). Precisa el propio autor del hallazgo, en carta dirigida a la Comisaría Provincial de Córdoba, que al principio no le atribuyó valor alguno, «porque cerca de allí se celebra desde siempre la tradicional feria de Córdoba, y lo creí un muñeco sin valor, por lo cual estuvo muchos años entre otros trastos en un sótano» (escrito de 4-101940, LRT, C25/39).

Romero de Torres aporta asimismo información adicional, tras entrevista mantenida con De las Morenas, como es la fecha de aparición del cervato, 16 años atrás, y que habría sido un coleccionista suizo quien le informara del extraordinario valor de la pieza, motivo por el cual la depositó en el MAN, cuyo director le propuso venderla al Estado por un precio de entre $2.000 \mathrm{y}$ 3.000 pesetas, oferta que fue rechazada. La fecha del hallazgo, sin embargo, es contradictoria: según dicha entrevista se habría producido hacia 1924, pero en un informe posterior remitido a Santa-Olalla afirma Romero de Torres que el cervato habría aparecido a finales de 1910, con anterioridad, por tanto, a la entrada en vigor de la Ley de Excavaciones de 1911 y en consecuencia de la completa propiedad de Federico de las Morenas. Dado que este, en el proceso de adquisición por el Estado de la pieza, no esgrime dicho argumento, nos inclinamos a considerar como cierta la primera (oficios de Romero de Torres de 21-7-1940 y 24-12-1942, LTR, C25/39 y 41).

El expediente de venta conservado en el MAN (Archivo MAN, 1943/41) permite contrastar la información aportada desde la Comisaría Provincial de Córdoba, a la que deliberadamente se intenta mantener al margen. Así, Romero de Torres no es informado ni del depósito de la pieza en el MAN, realizado con fecha 3 de febrero de 1940, ni de la razón de la visita realizada a Córdoba por Taracena (carta de Romero de Torres a Santa-Olalla de 14-11-1940, LRT, C25/39), en la que habría intentado que el propietario la donara al Estado «a cambio de alguna condecoración de Alfonso X el Sabio». El dueño solicita por carta al Museo 150.000 pesetas por la escultura, dada «su antigüedad y rareza», y ante la negativa de este a abonar tan abultada cantidad reclama la escultura (cartas de Federico de las Morenas, s/f y de 27-12-1941, Archivo MAN, 1943/41), que

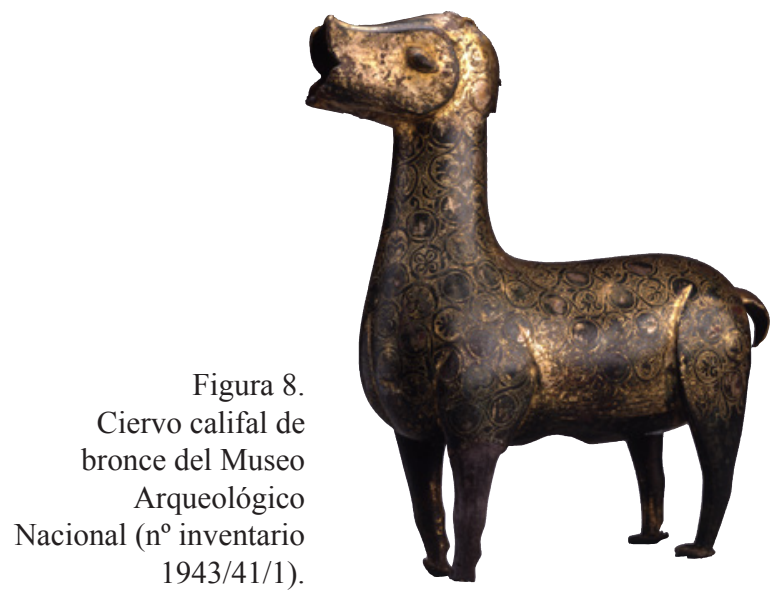

no le es devuelta bajo el argumento de que, de acuerdo con el citado art. 5 de la Ley de 1911, no tiene derecho alguno a reclamarla, por ser propiedad del Estado, afirmación que el posterior informe oficial corrobora tajantemente.

Estaríamos ante un estricto e inusual ejemplo de aplicación de la Ley de Excavaciones, si no fuera porque la respuesta "oficiosa" del Museo (copia de carta remitida a Federico de las Morenas, sin firma, de 6-51942, Archivo MAN, 1943/41) ofrece a De las Morenas la posibilidad de escoger entre considerar el depósito efectuado como un trámite previo a la aplicación del art. 5 o bien como una presentación del objeto para su libre adquisición por el Estado, recomendándole por razones obvias lo segundo. Aceptada la venta, el cervato fue valorado por el Patronato del MAN en 35.000 pesetas, siendo adquirido por OM de 30 de septiembre de 1943. Optar por la compra, en lugar del recurso a la expropiación, resultó probablemente una decisión más ventajosa para el propietario que para los intereses patrimoniales del Estado. El precio finalmente abonado por la pieza, 34.500 pesetas, fue muy superior a la cantidad inicialmente ofrecida por el Museo.

\subsubsection{Mosaicos de la calle Cruz Conde}

La calle Cruz Conde es una vía de nueva apertura, trazada en 1929 como ejemplo tardío de los planes de "ensanche interior" de los centros históricos, que cruza el ángulo noroeste de la ciudad histórica, desde finales del siglo XIX progresivamente convertido en el centro comercial y residencial burgués (García y Martín 1994: 33-37). La construcción de nuevos inmuebles a lo largo de toda la calle ofrece el mejor ejemplo de las escasas 


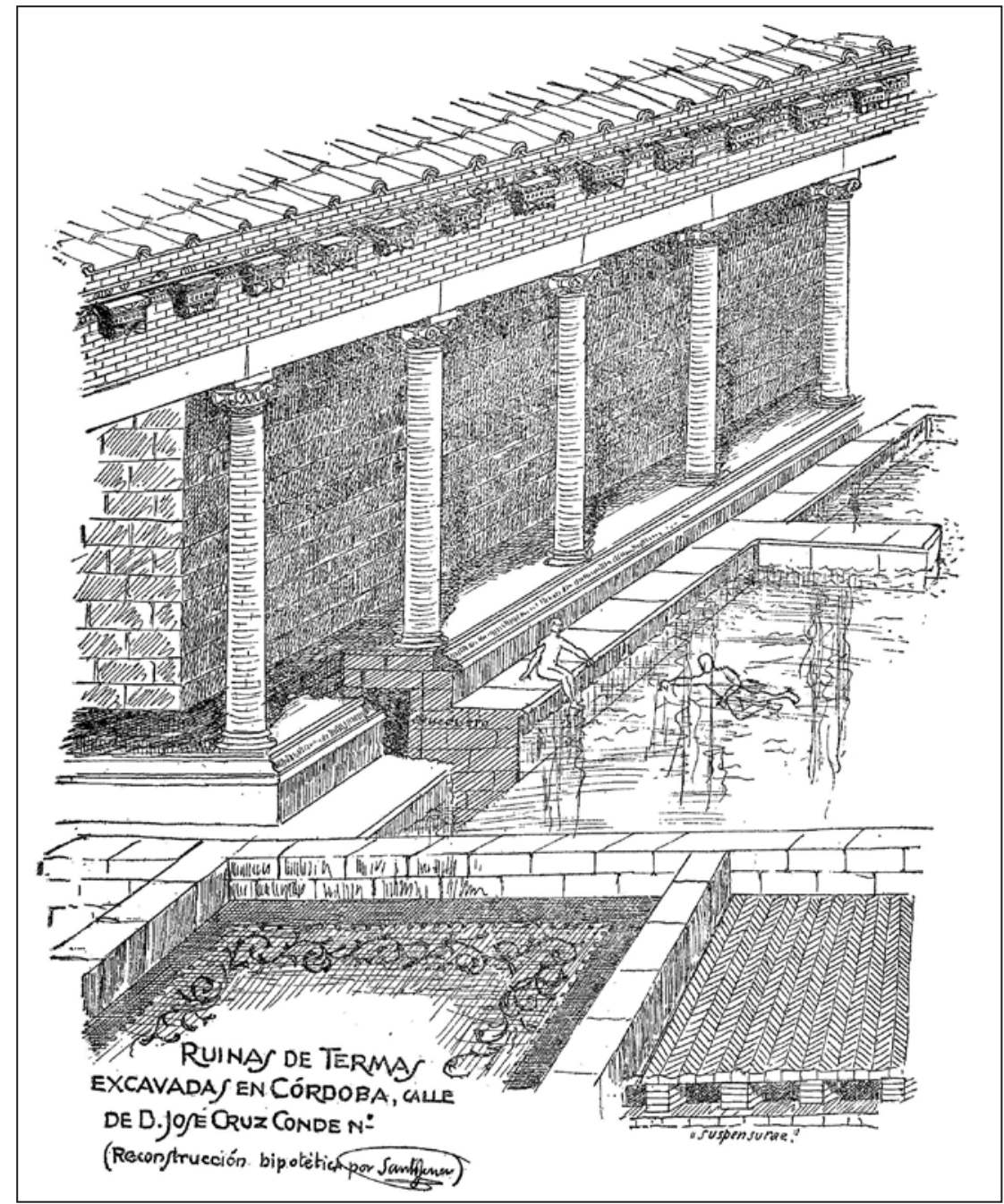

Figura 9.

Reconstrucción de las termas de c/ Cruz Conde esquina a c/ Cabrera (Santos 1955: 81). excavaciones de arqueología urbana realizadas en Córdoba durante la primera posguerra, junto con la intervención, más limitada, en el cercano convento de las Esclavas, situado en la plaza de San Juan, donde Santos Gener pudo documentar en los pozos de cimentación solería superficial de mármol, restos de muros de sillares romanos, y, a un nivel más profundo, una posible atarjea (Santos 1958: 91-94). En ambos casos la excavación estuvo motivada por la aparición de restos de mosaicos durante unas obras. En el caso de la calle Cruz Conde, es el propio Santos Gener quien en 1944 informa a la Comisaría Provincial de la aparición de un mosaico que el propietario del solar, Juan Cantera Berjillos, ocultó y destruyó, documentando una posterior inspección del arquitecto Félix Hernández restos de estructuras romanas (oficio de Santos Gener de 8-5-1944, LRT, C25/43). Las circunstancias del hallazgo son descritas en un texto que pese a su extensión no queremos dejar de reproducir por la claridad con que muestra las circunstancias a las que tanto Comisaría como $\mathrm{Mu}-$ seo Arqueológico habían de enfrentarse:

Se halló a unos $3 \mathrm{~m}$ de profd. un mosaico romano de tipo geométrico, junto al encañado de un pozo árabe revestido de atanores y relleno de cerámica califal y tierra. Pocos días después de este hallazgo avisaron al Museo (...) que fuésemos a ver el mosaico, pero aunque llegamos 10 minutos después ya lo habían roto. Días más tarde se descubrió otro mosaico de pavimento formado con losanjes de mármol blanco, verde y negro. Este lo destruyeron poco después, lo que provocó la denuncia de este Museo al Delegado de Excavaciones para que vigile estos trabajos como es debido. (...) ... en el $2^{\circ}$ trozo excavado junto al anterior se han hallado más restos del edificio romano allí enterrado. 
Por haber convenido con el Sr. Comisario de Excavaciones que éste se ocupase de todo lo referente a esta excavación no se ha obtenido hasta ahora dato alguno sobre la planta de cimientos y la situación en ella de los 4 basamentos de columnas estriadas allí encontradas. Todo lo han destruido, digo, destrozado, sin dejar plano. Supongo que las 4 basas sean restos de un peristilo de la casa allí existente. El Sr. Osuna me dijo que de allí sacaron trozos de fustes de columnas y un brazo desnudo de una estatua... (Santos 1958: 120-121).

En 1945, se repiten los hallazgos en la misma zona, calle de Cruz Conde esquina a calle Cabrera, solar propiedad en este segundo caso de Pedro de Pablos Barbudo. Junto con estructuras de habitación, «una serie de habitaciones romanas, pertenecientes a una gran casa», fueron encontrados un capitel incompleto y tres mosaicos, dos con motivos geométricos y el tercero «incompleto, pero con un emblema de "Pegaso" en el centro enmarcado en un rectángulo de soga. (...) Bajo los pavimentos se conservan unos pilarcillos formados por ladrillos cuadrados que no parecen de la organización del hipocaustum. El mosaico de Pegaso está bajo el nivel de rombos a unos 0,40 m por debajo. Las paredes o zócalos de la habitación de Pegaso están recubiertas de estuco pintado» (MAECO, DO000057/1; Santos 1958: 127). Los restos descritos se encuentran en un área muy próxima a los espacios forales de la antigua Colonia Patricia, cuya excavación, hasta aquel momento «la más trascendental de cuantas ruinas romanas han sido descubiertas en Córdoba» (Santos 1955: 76), pudo publicar en su Memoria de las Excavaciones del Plan Nacional Santos Gener, quien interpreta los restos hallados en el solar del Pegaso como unas termas (Santos 1955: 61-84; fig. 9).

Una vez más, los medios al alcance de las diversas instituciones responsables de la protección del patrimonio arqueológico no están a la altura de la magnitud del mismo. Carente la Comisaría de autoridad real, la única opción en esta y análogas circunstancias es informar al gobernador civil, rogando su colaboración para obligar al propietario a que, en cumplimiento de la Ley de Excavaciones, informara de los restos aparecidos y los depositara en el Museo Provincial (oficio de Romero de Torres de 30-5-1944, LRT, C25/43). Ni siquiera le es posible a la CGEA correr con los gastos del traslado de las piezas, en este caso los mosaicos del solar de Cruz Conde esquina a Cabrera, informando a Romero de Torres Alonso del Real que por falta de fondos «el traslado de los mosaicos deberá ser realizado por el Museo Arqueológico Provincial» (oficio de 6-2-1945, LRT, C25/44). Como este carecía asimismo de recursos, la intervención, probablemente

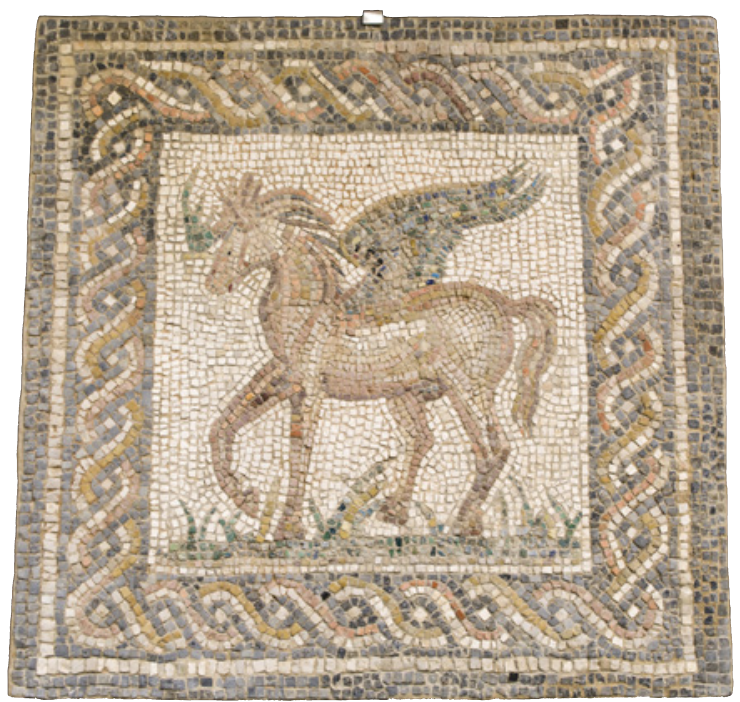

Figura 10. Mosaico con emblema de Pegaso aparecido en c/ Cruz Conde esquina a c/ Cabrera (MAECO, $n^{\circ}$ registro DO000057/1).

más a título personal que como comisario, de Romero de Torres ante el gobernador civil y la Diputación provincial consigue el libramiento de las 1.000 pesetas necesarias para el traslado, impidiendo que «hubiera quedado el mosaico sepultado bajo los cimientos de la casa que se construye en aquel lugar» (carta de Romero de Torres a Santa-Olalla de 12-2-1946, LRT, C25/9; fig. 10).

\subsubsection{Pila de la Alamiriya}

La primera de las conocidas como Pilas de la Alamiriya fue un hallazgo casual, producido durante las obras para construir un hotel en la finca La Gorgoja, considerada por Velázquez Bosco, su primer excavador, como la almunia Alamiriya o Alamiría, propiedad de Almanzor, si bien estudios posteriores la han identificado con al-Rummaniyya, almunia recibida por el califa Alhakén II como regalo de su tesorero (Velázquez 1912; Ocaña 1984). La pieza, una pila de fuente marmórea, decorada en sus cuatro caras con motivos vegetales y animales (MAECO, CE006418), fue adquirida gracias a las gestiones de la CPM por el Estado en 1929, ingresando en el Museo Arqueológico Provincial (Bugella 2017b: 259). En 1945 apareció una pila muy similar en la tienda de Juan Rodríguez Mora (fig. 11), hecho del que informó Romero de Torres a la CGEA. Afirmaba el anticuario, que pedía por la misma 10.000 pesetas, haberla adquirido de un vecino de la localidad de 
Almodóvar del Río, como aparecida en una finca cercana, si bien sobre su origen hay versiones contradictorias, pues al parecer podría también haberla adquirido a unos areneros, de segunda o tercera mano, por 50 pesetas. Romero de Torres, en su calidad de apoderado del SDPAN, comunicó a Rodríguez Mora que solicitaría a la DGBA la adquisición de la pieza, pero que mientras tanto esta no debía salir de Córdoba (carta de Romero de Torres a Santa-Olalla de 12-2-1946, LRT, C25/9).

La intervención de Romero de Torres parece finalizar tras su informe a la DGBA y a la CGEA. La nueva pila, en forma de artesa y decorada como la anterior en tres de sus lados con motivos florales y animalísticos (MAECO, CE009387), fue afortunadamente adquirida, al precio exigido por el vendedor, por Manuel GómezMoreno, a la sazón director del Instituto de Valencia de Don Juan, quien la donó al Museo Arqueológico de Córdoba (Castejón 1945b: 203; Santos 1950: 93).

\subsubsection{Tesorillo árabe}

En noviembre de 1945 ruega de nuevo Romero de Torres al gobernador civil su colaboración, en este caso para gestionar la entrega al Museo de un tesorillo árabe hallado en una finca de las afueras de Córdoba. Un oficio posterior remitido a la CGEA informa sin embargo de que el hallazgo había sido devuelto a su dueño por carecer de importancia, al tratarse no de monedas completas, sino de pequeños fragmentos (oficios de 9 y de 21-11-1945, LRT, C25/44). El conjunto había sido examinado por el director del Museo Arqueológico, quien brevemente lo describe como presentado por «un Sr. propietario de Córdoba, que me enseña un oficio del Gobernador en que se ordena de parte del Sr. Comisario de Excavaciones que entregue un lote de unas 25 monedas de plata árabes y un jarrito, todo muy malo» (Santos 1958: 137).

\subsection{Dimisión de Enrique Romero de Torres}

El humilde hallazgo que acabamos de mencionar aparece hermanado con el anterior, uno de los más importantes de la época estudiada, por constituir ambos la causa, si no determinante al menos final, de la dimisión de Enrique Romero de Torres del cargo de comisario provincial. En su escrito de dimisión (oficio de 12-2-1946, LRT, C25/9), remitido tanto al director de la DGBA como a Santa-Olalla, alega únicamente el mucho trabajo generado por sus investigaciones artísticas y ocupaciones privadas, en particular por su cargo de delegado de la CPM para la inclusión de Córdoba en el Tesoro Artístico Nacional. Sin embargo, con la misma fecha que las citadas misivas, 12 de febrero de 1946, responde Enrique a una carta previa del comisario general, a la que iban unidas dos comunicaciones (oficios y carta de Santa-Olalla de 2-1-1946, LRT, C25/9). La carta la califica de amistosa, pero de las comunicaciones afirma que son dos «palmetazos» a su labor como comisario provincial que no cree merecer. Se refiere la primera de ellas al último de los hallazgos reseñados, el de una ollita con «residuos de cuatro o cinco monedas árabes de plata», devuelta a su dueño por considerar Santos Gener «que no tenía importancia alguna». Se extraña Romero de Torres de que Santa-Olalla le censure su proceder, y se tome «tan a pecho este pequeño asunto», considerando en su escrito la devolución como «improcedente», pues «el dueño es el Estado» y la decisión tomada por el comisario provincial «resulta lamentable para los intereses del mismo y para futuros descubrimientos».

En cuanto a su actuación personal con respecto a la pila de la Alamiriya, objeto de la segunda de las comunicaciones, refuta los reproches de Santa-Olalla por haber intervenido en el asunto en calidad de apoderado del SDPAN y no como comisario provincial, siendo la CGEA, según su comisario general, el «único Organismo que legalmente está obligado y puede intervenir en asuntos de esa índole». Le argumenta que ambos cargos están legalmente acreditados para intervenir hallazgos arqueológicos, si bien mientras el SDPAN está «muy bien dotado para la adquisición de objetos» la Comisaría «carece de numerario», pues no tiene ni para transportar las piezas encontradas, recordándole al respecto lo ocurrido con el mosaico de la calle Cruz Conde. Se lamenta asimismo de que sistemáticamente los objetos de gran valor arqueológico acaban en las tiendas de los anticuarios, donde «son vendidos a precios altos impunemente, como ha ocurrido ahora, sin que hasta la presente se halla evitado a estos industriales que burlen a su antojo la Ley de Antigüedades». De la Comisaría Provincial afirma finalmente que, ya que no tiene medios, al menos debía tener más autoridad. Cita como ejemplo de esa carencia su ignorancia oficial del desarrollo de las excavaciones en Medina Azahara, donde se habían reanudado los trabajos sin que se le hubiera comunicado nada, habiendo tenido que enterarse de los detalles de su financiación por la prensa local, y por casualidad, a través de Rafael Castejón, de que Emilio Camps, que había sido apartado de la Comisión de Excavaciones a instancias de Santa-Olalla, 
había vuelto a pesar de ello a ser nombrado. Dimite por todo lo expuesto y «por otras causas que le explicaré de palabra y de modo confidencial, algunas de las cuales afectan a V. directamente».

Si la DGBA se limitó a aceptar la dimisión (oficio de 21-2-1946, LRT, C25/9), de la respuesta del comisario general no tenemos constancia documental hasta finales de ese mismo año, en que por carta manuscrita deplora Santa-Olalla la situación en que las circunstancias, y en parte él mismo, han colocado a Romero de Torres. Alude, sin más precisión, a la defensa que hizo de su nombramiento y termina afirmando su deseo de no prescindir de su amistad. La respuesta de Romero de Torres lamenta el disgusto que le ha causado con su dimisión, así como que para nombrarlo comisario tuviera en su momento que "defender" su propuesta. Espera, como su interlocutor, que no se enfríe su gran amistad, ofreciéndose a continuar su colaboración con la Comisaría fuera del cargo (cartas de Santa-Olalla de 18-111946 y de Romero de Torres, copia s/f, LRT, C25/9).

La dimisión pone fin a una serie de desencuentros rastreable en la correspondencia del año anterior, en particular en el oficio por el que Romero de Torres acusaba recibo de las circulares de la CGEA n ${ }^{\circ} 8$ y 9, de 7 de julio de 1946 (oficio de 18-9-1945, LRT, C25/44), dedicadas respectivamente al seguimiento de los hallazgos casuales y a las colecciones particulares de los comisarios, recordando la incompatibilidad entre este cargo y el de coleccionista en activo, y recomendando asimismo la publicación de las piezas adquiridas con anterioridad al nombramiento. Con respecto a la primera, afirma que viene cumpliéndola estrictamente en la capital, no así en los pueblos, por falta de numerario para sufragar los gastos del viaje, que en ocasiones ha debido abonar «de su peculio particular». Lamenta la falta de medios de la Comisaría, y la impunidad con que los anticuarios burlan la ley, siendo en ese momento cuando refiere el hallazgo de la pila de Alamiriya en la tienda de Rodríguez Mora.

Por lo que se refiere a la $n^{\circ} 9$, le recuerda que su colección arqueológica particular es muy anterior a su nombramiento como comisario, habiendo sido comenzada por su padre, Rafael Romero Barros, siendo además desde el año 1935 propiedad de su hermana Angelita. Si la explicación ofrecida no bastara para satisfacer a «algunos espíritus suspicaces» pone su cargo a disposición del Comisario General. Aunque no es objeto de este artículo, la citada colección se encontraba expuesta en el patio de la residencia familiar, ubicada en las dependencias del Museo de Bellas Artes de Córdoba, habiendo publicado la propia

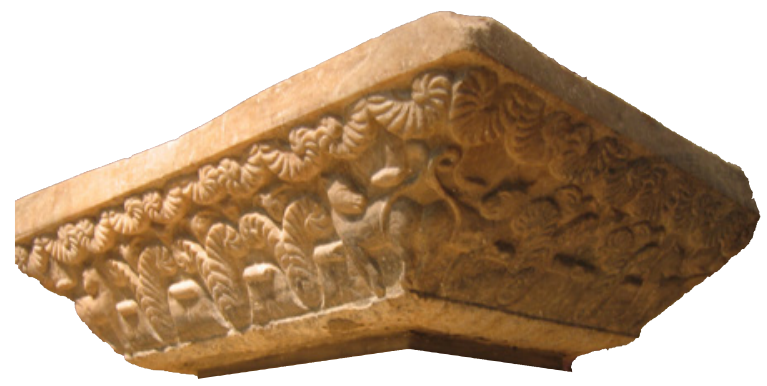

Figura 11. Pila de la Alamiriya (MAECO, $\mathrm{n}^{\circ}$ registro CE009387).

Angelita en las Memorias de los Museos Arqueológicos Provinciales los pormenores de su origen y piezas más destacadas de la misma (Romero de Torres 1943). Fue adquirida a la familia por la Junta de Andalucía en 1989, junto con el archivo familiar, siendo asignada al propio Museo de Bellas Artes en el que ya se encontraba depositada.

\section{CONCLUSIONES}

Una de las causas, si no la principal, de los problemas que arrastraría la CGEA fue la forma en que Martínez Santa Olalla empezó a gestionar el poder y las atribuciones de su cargo. Actuó más movido por su resentimiento personal que como administrador y organizador, sin reparar a quién y por qué dirigía sus ataques, ni las posibles conexiones políticas o personales de aquellos a los que convertía en blanco de sus invectivas, y que tenían la posibilidad de volverse contra él con posibilidades de éxito. (Gracia 2009: 228-229).

Lo afirmado por F. Gracia parece cumplirse en el caso de Romero de Torres. Pese a la dedicación de que hizo gala durante los cinco años en que ocupó el cargo, y a las promesas de amistad intercambiadas por ambos, el comisario provincial hubo de hacer frente a unas exigencias que no creemos exagerar si calificamos de abrumadoras, por la exhaustividad de los pormenores requeridos e incluso su misma reiteración. Quede como ejemplo final de este último aspecto que a finales de 1945 aún demandaba Santa-Olalla información sobre la fecha y el lugar exactos del hallazgo del cervato del MAN (oficio de 6-12-1945, LRT, C25/44).

El problema más grave que sin embargo lastró desde sus comienzos a la CGEA y la hizo finalmente inoperante fue la falta de medios, incluyendo en dicha carencia no solo los económicos sino, quizá más 
relevante, la falta de auténtica capacidad de actuación de la propia institución y de quienes intervenían en su nombre. La única autoridad que reviste a Romero de Torres deriva de su cargo de director del Museo de Bellas Artes y de su pertenencia a una conocida familia de la intelectualidad local, un perfil semejante al que acompañó a los dos posteriores comisarios locales, Samuel de los Santos Gener y Rafael Castejón y Martínez de Arizala, quienes, como Romero de Torres, hubieron de compaginar las obligaciones del nuevo cargo con múltiples responsabilidades profesionales. Ambos difieren de aquel, curiosamente, en su "desafección" al régimen franquista, hecho que convierte en una singularidad su nombramiento, para el que lo habitual era tener muy en cuenta la valoración ofrecida por el preceptivo informe confidencial de la autoridad política competente, y que en más de un caso imposibilitó el acceso al cargo (Díaz-Andreu y Ramírez 2001: 331-335).

El personalismo del comisario general es el tercer problema que parece colmar el vaso de la paciencia de Romero de Torres. El trato displicente que motiva su dimisión es posible rastrearlo, con mayor o menor intensidad, en casi toda la correspondencia por él emitida, y su distanciamiento del mundo universitario e incluso de la propia DGBA se traduce en que la institución que preside es obviada, casi cabría decir que ninguneada, en los asuntos casualmente más relevantes del periodo estudiado, las excavaciones de Medina Azahara y la adquisición de piezas clave como el cervato del MAN y la pila de la Alamiriya.

La dimisión de Romero de Torres se produce en vísperas de lo que podríamos considerar un punto de inflexión en la evolución de la CGEA, el II Congreso del Sudeste Español. Celebrado entre los días 21 y 23 de marzo de 1946 en Albacete, en él se discutieron los problemas a los que se enfrentaban los comisarios, si bien la cuestión más debatida giró en torno a la figura del arqueólogo como profesional o como erudito vinculado. La falta de preparación de este último parecía sugerir, como solución, una mayor profesionalización e influencia de la Universidad, e incluso la ponencia presentada por Carlos Alonso del Real, que defendía que un arqueólogo investigador no tenía por qué pertenecer únicamente al ámbito universitario, «abogaba por una creciente profesionalización de la arqueología, y la dirección de la investigación desde las universidades y los centros de investigación» (Gracia 2009: 371 373).

Fruto quizá de su carencia de formación específica sea la innegable mentalidad anticuarista presente en toda la actividad arqueológica de Enrique Romero de Torres. Actitud inevitable, creemos, en el contexto en el que trabajó, y compartida además por arqueólogos profesionales como Santos Gener o el propio Santa-Olalla. Dicha mentalidad se hace visible en su tendencia a sobrevalorar las piezas, especialmente las de mérito artístico, muy por encima del contexto arqueológico en que aparecen y de la información científica que de ambos se pueda obtener. Preside asimismo la formación de la colección arqueológica familiar, que tiñe de ambigüedad no sólo su labor como comisario, sino todo su trabajo como arqueólogo. Aunque nominalmente propiedad de su hermana, él es el responsable de acrecentarla y a quien se realizan las numerosas donaciones de piezas que en muchos casos debieron haber engrosado las colecciones del Museo Arqueológico Provincial (LRT, C27). Hemos de considerar, sin embargo, que quienes realizaron esos donativos a una colección privada lo hicieron en atención a la condición de funcionario público de su propietario, $\mathrm{y}$, sobre todo, a su prestigio profesional y a su encendida defensa del legado histórico y artístico de su tierra natal, rasgos que, junto con la inmensa capacidad de trabajo de que hizo gala hasta el final de sus días, aún debemos hoy respetar y admirar.

\section{BIBLIOGRAFÍA}

Aguilar, E.; García, M. A.; Ortiz, J. y Toribio, M. (2014): Cuatro cordobeses para la historia: Francisco Azorín Izquierdo, Rafael Castejón y Martínez de Arizala, Antonio Jaén Morente, Eloy Vaquero Cantillo. Córdoba, Renacimiento.

Alegre Ávila, J. M. (1994): Evolución y régimen jurídico del patrimonio histórico. Madrid, Ministerio de Cultura.

Aulló Costilla, M. (1924/25): Excavaciones arqueológicas en diversos yacimientos sitos en las provincias de Segovia y Córdoba. Memorias de la Junta Superior de Excavaciones y Antigüedades 71. Madrid, Revista de Archivos, Bibliotecas y Museos.

Blánquez, J. y Roldán, L. (2011/12): “El legado fotográfico y planimétrico de Julio Martínez SantaOlalla". Cuadernos de Prehistoria y Arqueología de la Universidad Autónoma de Madrid 37/38: 53-73. Disponible en: https://doi.org/10.15366/cupauam2012.38.003

Beltrán Fortes, J. (2011): "Historia de la Arqueología andaluza de 1860 a 1936. En el marco vital de 
Luis Siret (1860-1934)", en M. Sánchez Romero M. (coord.), Memorial Luis Siret. I Congreso de Prehistoria de Andalucía. La tutela del patrimonio prehistórico: 25-38. Antequera (2010), Sevilla, Consejería de Cultura de la Junta de Andalucía.

Bugella Altamirano, M. (2016a): "El Tesoro de Córdoba. Comercio ilegal de antigüedades durante el primer tercio del siglo XX”. Anales de Arqueología Cordobesa 27: 11-34.

Bugella Altamirano, M. (2016b): "La Comisión Provincial de Monumentos de Córdoba y la preservación del patrimonio arqueológico. Los baños árabes de la calle Pescadería", en A. F. Chica y J. Mérida (eds.), Creando redes doctorales, vol. V: 5-8. Córdoba, Universidad de Córdoba.

Bugella Altamirano, M. (2017a): "La protección jurídica del patrimonio arqueológico. De la Real Cédula de 1803 a la Guerra Civil". Patrimonio Cultural y Derecho 21: 319-334.

Bugella Altamirano, M. (2017b): "El Museo Arqueológico de Córdoba y la Comisión Provincial de Monumentos. Memoria de una relación", en A. Carretero; C. Papí y G. Ruiz (eds.), Actas del V Congreso Internacional de Historia de la Arqueologíal IV Jornadas de Historiografía SEHA-MAN: 249264. Madrid (2017), Madrid, Museo Arqueológico Nacional.

Bugella Altamirano, M. (2018): “Capiteles islámicos cordobeses en el Museo Arqueológico Nacional. Breve historia de un largo trayecto". Boletín del Museo Arqueológico Nacional 37: 167-183.

Camps Cazorla, E. (1943): "Un nuevo «ciervo» califal de bronce". Archivo Español de Arte 58: 212-222.

Cabello Carro, P. (2013): "Inicio de las políticas de conservación del Patrimonio Histórico en 1900 y creación de la Dirección General de Bellas Artes en 1915". Patrimonio Cultural y Derecho 17: 35-70.

Carbonell Trillo-Figueroa, A. (1927): "Contribución al estudio de la Prehistoria cordobesa: la zona de Villanueva de Córdoba". Boletín de la Real Academia de Córdoba 19: 413-430.

Castejón y Martínez de Arizala, R. (1925): “el plano de Medina Azahara". Boletín de la Real Academia de Córdoba 11: 22-15.

Castejón y Martínez de Arizala, R. (1945a): Excavaciones del Plan Nacional en Medina Azahara (Córdoba). Campaña de 1943. Informes y Memorias de la Comisaría General de Excavaciones 8. Madrid, Ministerio de Educación Nacional.

Castejón y Martínez de Arizala, R. (1945b): “La nueva pila de Alamiría, y las representaciones zoomórficas califales". Boletín de la Real Academia de Córdoba 53: 197-211.

Castelo, R.; Cardito, L.; Panizo, I. y Rodríguez, I. (1997): “Julio Martínez Santa-Olalla. Vinculación y contribución a los organismos e instituciones arqueológicas españolas de posguerra", en G. Mora y M. Díaz-Andreu (eds.), La cristalización del pasado: génesis y desarrollo del marco institucional de la Arqueología en España. Congreso de Historiografía de la Arqueología en España, siglos XVIII a XX: 573-580. Madrid (1995), Málaga, Universidad de Málaga y Consejo Superior de Investigaciones Científicas.

De los Santos Gener, S. (1940/41): "Sarcófagos romanos de plomo hallados en Córdoba". Archivo Español de Arqueología 14: 438-440.

De los Santos Gener, S. (1950): Guía del Museo Arqueológico Provincial de Córdoba. Madrid, Cuerpo Facultativo de Archiveros, Bibliotecarios y Arqueólogos.

De los Santos Gener, S. (1955): Memoria de las Excavaciones del Plan Nacional realizadas en Córdoba (1948-50). Informes y memorias de la Comisaría General de Excavaciones 31. Madrid, Ministerio de Educación Nacional.

De los Santos Gener, S. (1958): Registro de hallazgos arqueológicos en la provincia de Córdoba, recogidos y croquizados diariamente. Centro CIL II, Universidad de Alcalá de Henares. Inédito.

Díaz-Andreu García, M. (2002): Historia de la Arqueología. Estudios. Madrid, Ediciones Clásicas.

Díaz-Andreu García, M. (2003): "Arqueología y dictaduras: Italia, Alemania y España”, en F. Wulff y M. Álvarez (eds.), Antigüedad y franquismo: 33-74. Málaga, Diputación de Málaga.

Díaz-Andreu García, M. (2011): "La historia de la Prehistoria andaluza durante el periodo franquista (1939-1975)", en M. Sánchez Romero (coord.), Memorial Luis Siret. I Congreso de Prehistoria de Andalucía. La tutela del patrimonio: 39-72. Antequera (2010), Sevilla, Consejería de Cultura de la Junta de Andalucía.

Díaz-Andreu, M. y Ramírez, M. (2001): “La Comisaría general de excavaciones arqueológicas (19391955). La administración del patrimonio arqueológico en España durante la primera etapa de la dictadura franquista". Complutum 12: 325-343.

García, F. R. y Martín, C. (1994): Cartografia y fotografía de un siglo de urbanismo en Córdoba, 18511958. Córdoba, Gerencia de Urbanismo del Ayuntamiento de Córdoba. 
Garriguet Mata, J. A. (2009/10): "Samuel de los Santos Gener y los inicios de la Arqueología urbana en Córdoba". Anejos de Anales de Arqueología Cordobesa 2: 11-18.

Gonzalbes Cravioto, E. (2015): “Arqueología española para un nuevo régimen: Martínez Santa-Olalla y el norte de Marruecos". Onoba 3: 3-14.

Gracia Alonso, F. (2009): La arqueología durante el primer franquismo (1939-1956). Barcelona, Bellaterra. Disponible en: https://doi.org/10.5334/ bha.20206.

Jiménez Amigo, R. (1924): Excavaciones en Medina Azzahra (Córdoba): memoria de los trabajos realizados por la Comisión delegado-directora de los mismos. Memorias de la Junta Superior de Excavaciones y Antigüedades 67. Madrid, Revista de Archivos, Bibliotecas y Museos.

Leiva Briones, F. (2007): "Acerca de la arqueología de Fuente-Tójar (Córdoba): hallazgos y excavaciones". Boletín de la Asociación Provincial de Museos Locales de Córdoba 8: 301-362.

Lucas Pellicer, M. R. (1991): “La arqueología no profesional: antecedentes y panorama actual", en J. Arce y R. Olmos (coords.), Historiografía de la Arqueología y la Historia Antigua en España (siglos XVIII-XX). Congreso Internacional: 237-242. Madrid (1988), Madrid, Instituto de Conservación y Restauración de Bienes Culturales.

Martín Urdíroz, I. (2002): "Enterramientos sarcofágicos de plomo en Corduba", en D. Vaquerizo (ed.), Espacio y usos funerarios en el Occidente romano: actas del Congreso Internacional, vol. 2: 311-324. Córdoba (2001), Córdoba, Universidad de Córdoba.

Mederos Martín, A. (2003/04): “Julio Martínez SantaOlalla y la interpretación aria de la Prehistoria". Boletín del Seminario de Estudios de Arte y Arqueología, 69-70: 13-56.

Ocaña Jiménez, M. (1984): “Las ruinas de Alamiría, un yacimiento arqueológico erróneamente denominado". Al-qantara: Revista de estudios árabes 5.12: 367-382.

Palencia Cerezo, J. M. (2006): Enrique Romero de Torres. Córdoba, Consejería de Cultura de la Junta de Andalucía.

Papí, C. y Balmaseda, L. (2008): “Sobre arqueología y anticuarios hispanos en el segundo tercio del siglo XX: Juan Rodríguez Mora y sus ventas al MAN", en Jornadas de Historiografía. Documentos inéditos para la Historia de la Arqueología: 85-98. Madrid (2007), Madrid, Sociedad Española de Historia de la Arqueología y Museo Arqueológico Nacional.
Quero Castro, S. (2015): "El archivo documental del Museo de San Isidro de Madrid". Cuadernos de Prehistoria y Arqueología de la Universidad Autónoma de Madrid 41: 97-108. Disponible en: https:// doi.org/10.15366/cupauam2015.41.007.

Romero de Torres, A. (1943): “Colección Arqueológica Romero de Torres. Córdoba". Memorias de los Museos Arqueológicos Provinciales IV: 205-208.

Romero de Torres, E. (1941): "Tumba romana descubierta en el Camino Viejo de Almodóvar (Córdoba)", en J. Martínez Santa-Olalla (ed.), Corona de estudios que la Sociedad Española de Antropología, Etnografía y Prehistoria dedica a sus Mártires I: 323-326. Madrid, Consejo Superior de Investigaciones Científicas.

Vallejo Triano, A. (2010): La ciudad califal de Madinat al-Zahra. Arqueología de su excavación. Córdoba, Almuzara.

Vaquerizo, D.; Murillo, F. y Quesada, F. (1992): "Excavación arqueológica con sondeos estratigráficos en Cerro de las Cabezas (Fuente Tójar, Córdoba). Campaña de 1991. Avance a su estudio". Anales de Arqueología Cordobesa 3: 171-197.

Velázquez Bosco, R. (1912): Medina Azahara y Alamiriya. Arte del Califato de Córdoba. Madrid, Junta para la Ampliación de Estudios e Investigaciones Científicas.

Velázquez Bosco, R. (1923): Excavaciones en Medina Azahara. Memoria sobre lo descubierto en dichas excavaciones. Madrid, Junta Superior de Excavaciones y Antigüedades.

\section{Fondos documentales}

Fondo documental de la familia Romero de Torres. Archivo Provincial de Córdoba. Cajas $n^{\circ} 24,25$ y 27.

Archivo del Museo Arqueológico Nacional. Carpetas $n^{\circ} 1943 / 11,1943 / 41$ y $1949 / 13$.

\section{Legislación}

$\mathrm{N}^{\mathrm{o}}$ 1, Ley de Excavaciones y Antigüedades, Gaceta de Madrid n ${ }^{\circ} 189$, Madrid, 8 de julio de 1911, pp. 9596.

$\mathrm{N}^{\mathrm{o}}$ 2, Ley relativa al Patrimonio Artístico Nacional, Gaceta de Madrid n ${ }^{\circ}$ 145, Madrid, 25 de mayo de 1933, pp. 1.393-1.399. 